\title{
An Overview of Linear Dielectric Polymers and Their Nanocomposites for Energy Storage
}

\author{
Lvye Dou ${ }^{1,2}$, Yuan-Hua Lin ${ }^{1, *}$ and Ce-Wen Nan ${ }^{1}$ \\ 1 State Key Laboratory of New Ceramics and Fine Processing, School of Materials Science and Engineering, \\ Tsinghua University, Beijing 100084, China; lvyedu1102@tsinghua.edu.cn (L.D.); \\ cwnan@tsinghua.edu.cn (C.-W.N.) \\ 2 Foshan (Southern China) Institute for New Materials, Foshan 528000, China \\ * Correspondence: linyh@tsinghua.edu.cn or linyh@mail.tsinghua.edu.cn
}

Citation: Dou, L.; Lin, Y.-H.; Nan, C.-W. An Overview of Linear Dielectric Polymers and Their Nanocomposites for Energy Storage. Molecules 2021, 26, 6148 . https://doi.org/10.3390/ molecules26206148

Academic Editors: Giuseppe Cirillo and Chongjun Zhao

Received: 6 September 2021

Accepted: 1 October 2021

Published: 12 October 2021

Publisher's Note: MDPI stays neutral with regard to jurisdictional claims in published maps and institutional affiliations.

Copyright: (C) 2021 by the authors Licensee MDPI, Basel, Switzerland. This article is an open access article distributed under the terms and conditions of the Creative Commons Attribution (CC BY) license (https:/ / creativecommons.org/licenses/by/ $4.0 /)$.

\begin{abstract}
As one of the most important energy storage devices, dielectric capacitors have attracted increasing attention because of their ultrahigh power density, which allows them to play a critical role in many high-power electrical systems. To date, four typical dielectric materials have been widely studied, including ferroelectrics, relaxor ferroelectrics, anti-ferroelectrics, and linear dielectrics. Among these materials, linear dielectric polymers are attractive due to their significant advantages in breakdown strength and efficiency. However, the practical application of linear dielectrics is usually severely hindered by their low energy density, which is caused by their relatively low dielectric constant. This review summarizes some typical studies on linear dielectric polymers and their nanocomposites, including linear dielectric polymer blends, ferroelectric/linear dielectric polymer blends, and linear polymer nanocomposites with various nanofillers. Moreover, through a detailed analysis of this research, we summarize several existing challenges and future perspectives in the research area of linear dielectric polymers, which may propel the development of linear dielectric polymers and realize their practical application.
\end{abstract}

Keywords: linear dielectric polymers; nanocomposites; energy storage capacitor; discharge density; efficiency

\section{Introduction: Basic Knowledge of Dielectric Capacitors}

The ever-increasing development of new energy generation technologies has led to higher requirements for the development and performance improvement of energy storage devices [1]. To date, the most commonly used energy storage devices mainly include dielectric capacitors [2,3], electrochemical capacitors [4,5], batteries [6,7], and fuel cells [8,9]. Among them, dielectric capacitors are competitive due to their ultrahigh power density [10]. However, compared with electrochemical capacitors and batteries, dielectric capacitors usually exhibit an ultralow energy density, as shown by the Ragone plot presented in Figure 1a [11]. As a result, dielectric capacitors are used for critical applications in various electrical systems but their low energy density significantly limits the miniaturization of devices $[12,13]$. Therefore, the energy storage performance of dielectrics must be significantly improved to enable their extensive practical application [14,15].

Figure $1 \mathrm{~b}$ shows the basic structure of a dielectric capacitor: a middle layer containing a dielectric material, with a conductive plate (electrode) on each side [1,16]. Once an electric field, E, is applied to the capacitor, the dielectric material between the electrodes is quickly polarized. Therefore, positive and negative charges of the same amount are separately accumulated on the two electrodes. The energy storage ability of a dielectric capacitor is defined as capacitance $(C)$, which is usually expressed as shown in Equation (1).

$$
C=\varepsilon_{\mathrm{r}} \varepsilon_{0} \frac{A}{d}
$$


In Equation (1), $\varepsilon_{\mathrm{r}}$ represents the permittivity of a dielectric material, and the value of $\varepsilon_{\mathrm{r}}$ is determined by its intrinsic properties. Thus, $\varepsilon_{0}$ is the vacuum permittivity, which is a constant value of $\sim 8.85 \times 10^{-12} \mathrm{~F} / \mathrm{m}$. $A$ and $d$ are the area of the electrode and the distance between the two electrodes (the thickness of the dielectric material), respectively. $C$ is directly proportional to $\varepsilon_{\mathrm{r}}$ and $A$, and it is inversely proportional to $d[1,2]$.
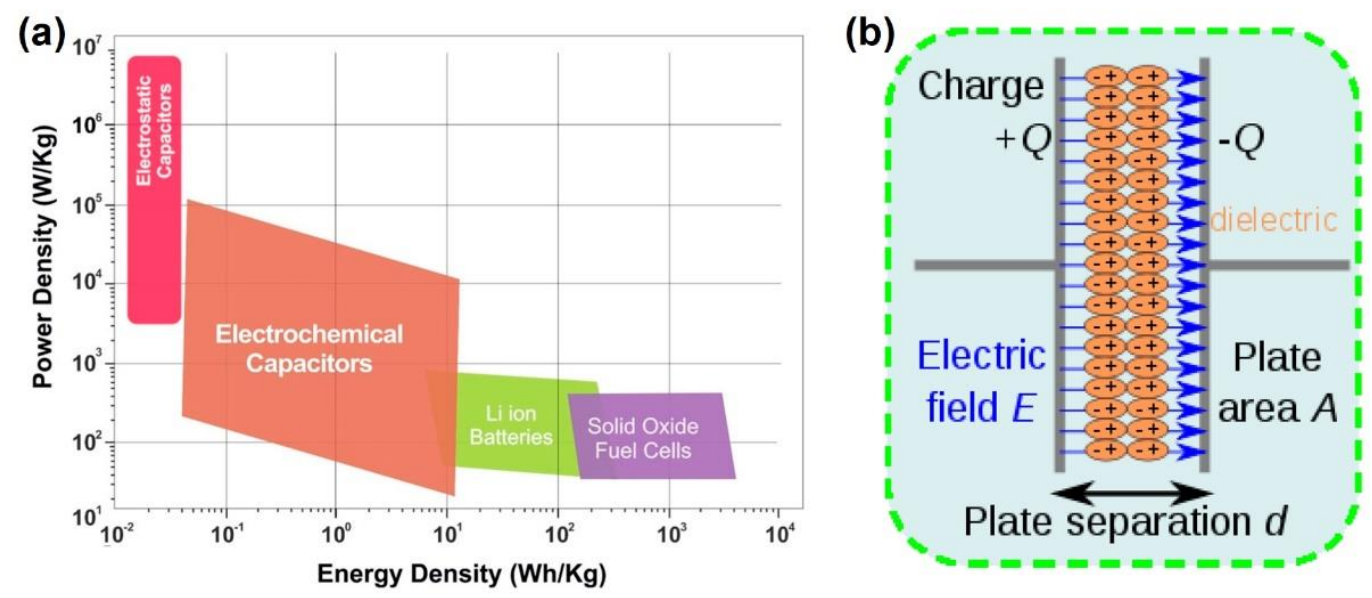

Figure 1. (a) Sketch of a Ragone plot for various energy storage device systems. Reproduced with permission from Ref. [11]. Copyright 2017, American Institute of Physics. (b) The diagram of charge separation in a parallel-plate capacitor under the function of an electric field. Reproduced with permission from Ref. [1]. Copyright 2013, World Scientific.

The capacitance $C$ can also be defined according to the incremental change of the charge $(Q)$ with respect to voltage $(V)$ and defined geometrically using the following equation:

$$
C=\frac{d_{Q}}{d_{V}}
$$

In this equation, $V$ is the external voltage applied to the two conductive plates and $Q$ represents the equal positive and negative charges accumulated on both conductive plate surfaces. Therefore, the energy stored in a dielectric material $(W)$ can be expressed as:

$$
W=\int_{0}^{Q_{\max }} V d_{Q}
$$

The charge density $(Q / A)$ on the plate surfaces equals the electric displacement $D$ (where $D=\varepsilon_{0} \varepsilon_{\mathrm{r}} E$ ) in the dielectric material. Therefore, according to Equation (3), the energy density $J$ can be expressed by the following equation [17]:

$$
J=\frac{W}{A d}=\frac{\int_{0}^{Q} V d_{Q}}{A d}=\int_{0}^{D_{\max }} E d D
$$

where $E$ is the external applied electric field (equal to $V / d$ ) and $D_{\max }$ is the electric displacement under the field $E_{\max }$. For dielectrics with high permittivity, the electric displacement $D$ is very close to the electric polarization $P$. Thus, Equation (4) can be rewritten as:

$$
J=\int_{0}^{P_{\max }} E d P=\int_{0}^{E_{\max }} \varepsilon_{0} \varepsilon_{\mathrm{r}} E d E
$$

By combining Equation (5) with the $P-E$ curve shown in Figure 2, the value of $J$ can be obtained by integrating the curves of the $P-E$ loop $[18,19]$. Thus, the blue-colored region in Figure 2 represents the recoverable energy density $\left(J_{\text {reco }}\right)$, while the green shaded region represents the energy density dissipated during the discharge process $\left(J_{\text {loss }}\right)$ [18]. The $J_{\text {reco }}$ can be improved in two ways: by enhancing the breakdown strength and increasing the polarization. 


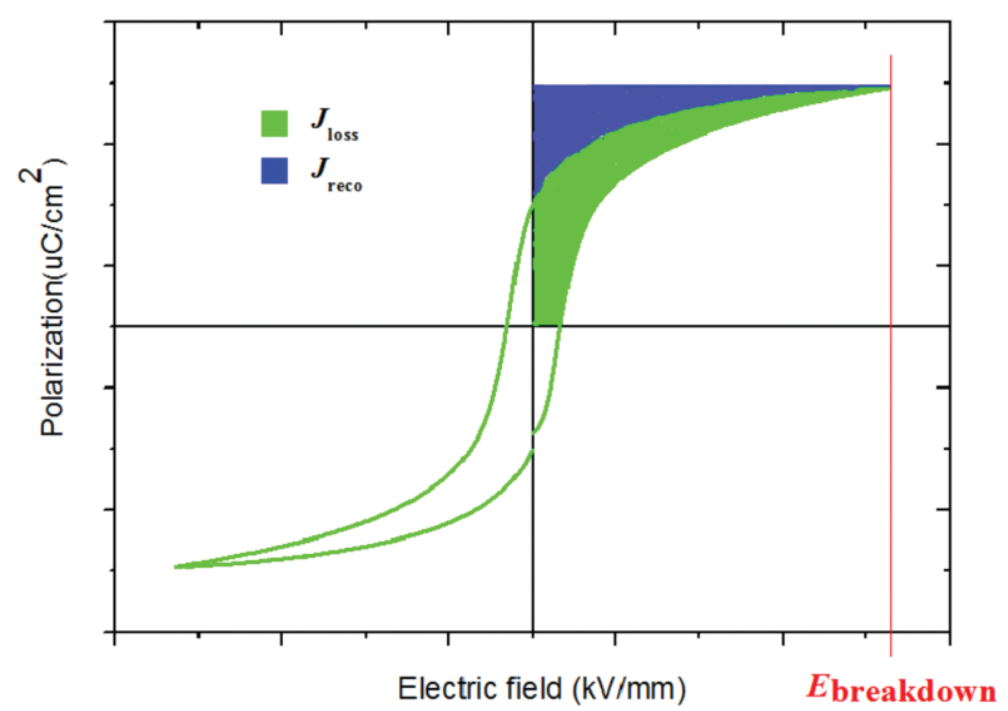

Figure 2. Graphical representation of a $P-E$ loop used for energy-storage calculations. Reproduced with permission from Ref. [18]. Copyright 2017, Wiley-VCH.

Generally, $J_{\text {loss }}$ is caused by leakage and polarization hysteresis. On this basis, the charge-discharge efficiency $\eta$ is defined as:

$$
\eta=\frac{J_{\text {reco }}}{J_{\text {reco }}+J_{\text {loss }}} \times 100 \%
$$

For linear dielectrics, the dielectric constant is independent of the electric field. Thus, the energy density of linear dielectrics is expressed by Equation (7):

$$
J=\frac{1}{2} \varepsilon_{0} \varepsilon_{\mathrm{r}} E^{2}
$$

where the value of $J$ is proportional to the value of $\varepsilon_{\mathrm{r}}$ and the square of $E[11,18]$.

\section{Classification of Dielectric Materials}

\subsection{Four Typical Dielectric Materials}

As the core component of dielectric capacitors, the intrinsic characteristics of dielectrics have a great impact on the energy storage performance of the capacitor. Dielectric capacitors will only be widely used in practical applications if they can exhibit high recoverable energy storage density and efficiency. To achieve this goal, three basic requirements need to be satisfied: high breakdown strength, high saturation polarization, and low remnant polarization [20]. To date, four typical dielectrics (ferroelectric, relaxor ferroelectric, antiferroelectric, and linear dielectrics) have been widely studied. The domain structure, electroactive behavior, and permittivity vs. the electric field of these dielectric materials are presented in Figure 3 [21].

As Figure 3a demonstrates, the D-E curves of ferroelectrics during the chargingdischarging process exhibit remarkably nonlinear characteristics, and the permittivity shows a decreasing tendency with the increasing electric field [21,22]. In addition, ferroelectrics often exhibit high remnant polarization $\left(P_{\text {rem }}\right)$, leading to a typical rectangularshaped hysteresis loop, as can be seen from the electroactive behavior of ferroelectrics, shown in Figure 3a. The apparent hysteresis loops in ferroelectrics are mainly caused by the switching of large ferroelectric (FE) domains [23,24]. Overall, ferroelectrics usually exhibit relatively high energy densities because of the relatively high saturation polarization $\left(P_{\text {sat }}\right)$ and moderate breakdown strength. However, the high $P_{\text {rem }}$ values result in low efficiency. 

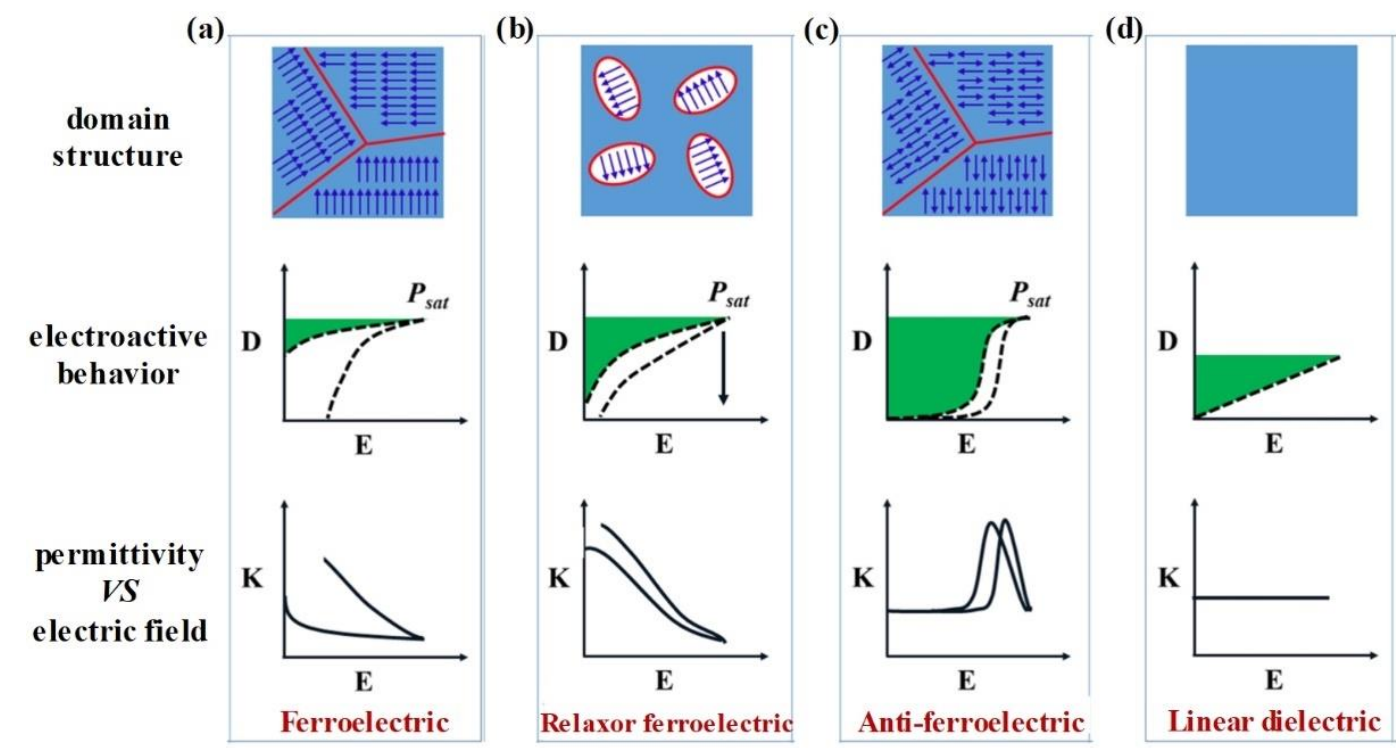

Figure 3. Schematic showing the typical classification of dielectric materials (a) Ferroelectric, (b) Relaxor ferroelectric, (c) Anti-ferroelectric, (d) Linear dielectric. Reproduced with permission from Ref. [21]. Copyright 2018, Elsevier.

Compared to ordinary ferroelectrics, the nanodomain structure of relaxor ferroelectrics is more disordered. The dispersion distribution of their structure and polarization leads to a dispersion distribution of macroscopic dielectric properties. Due to their small domain size and low energy barriers, these nanodomain structures are easily disturbed by thermal excitation or by flipping the electric field [25]. In addition, coupling between the domains is weak and the energy consumption of domain inversion is reduced, leading to a relatively low remnant polarization. As a result, low loss (and thus high efficiency) is achieved while maintaining high polarization, leading to a narrow hysteresis loop (Figure 3b).

As shown by Figure 3c, the electric behavior of antiferroelectrics is quite different from that of ferroelectrics and relaxor ferroelectrics. Specifically, the $P_{\text {rem }}$ of antiferroelectrics is zero, and the D-E curves of antiferroelectrics during the charging and discharging process display a double hysteresis loop [1]. Accordingly, the permittivity of antiferroelectrics remains constant at a low electric field but if the electric field increases, the permittivity first sharply increases and then rapidly decreases. The distinctive energy storage behavior of antiferroelectrics is mainly due to their unique domain structure. As presented in Figure 3c, the spontaneous polarization directions of adjacent dipoles in antiferroelectrics alternate in opposite directions, although polarization direction can be induced to have the same orientation under the function of an electric field [26,27].

Unlike the other three typical dielectric materials, linear dielectrics exhibit a linear D-E loop, and their permittivity remains constant under an increasing electric field (Figure 3d), which is mainly due to the lack of an FE domain [21,23]. Therefore, linear dielectrics generally possess a high electric breakdown strength with almost no energy loss, making them suitable for use in high-efficiency capacitors. However, linear dielectrics usually exhibit a relatively low permittivity. For example, the permittivities of commercial biaxially oriented polypropylene (BOPP) [28], polyetherimide (PEI) [29], and polyethylene terephthalate (PET) [30] are 2.2, 3.2, and 3.3, respectively. Therefore, the energy density of these materials will be significantly improved with the increase of the dielectric constant. Based on this analysis, a significant amount of research has been carried out, and select detailed methods will be discussed in Section 3 of this review. 


\subsection{Linear Dielectric Polymers}

In the early development of dielectric capacitors, piezoelectric ceramics were regarded as the most promising dielectric materials due to their high dielectric constants [31]. However, these ceramics usually exhibit low breakdown strength, making them unfavorable for improving capacitor energy density. In addition, the practical application of ceramics is severely limited by their poor flexibility and high density [32]. In contrast to ceramic dielectrics, polymer dielectrics usually exhibit higher breakdown strength, better flexibility, and improved ease of processing [33]. Therefore, polymer dielectric materials are more suitable for the fabrication of dielectric capacitors with improved energy storage performance $[24,34,35]$.

As mentioned in Section 2.1, linear dielectrics exhibit nearly linear D-E loops, due to their field-independent dielectric constant. Because of this, linear dielectrics usually exhibit higher efficiency than ferroelectrics. Therefore, in the past decades, researchers have carried out a significant amount of research on linear polymer dielectrics. In this section, several typical linear dielectric polymers will be briefly introduced.

\subsubsection{BOPP}

Currently, BOPP is one of the most commonly used commercial dielectrics, due to its excellent breakdown strength and the low dielectric loss of polypropylene (PP) [36]. $\mathrm{PP}$ is a typical linear dielectric polymer that exhibits nearly frequency-independent and temperature-independent permittivity. Therefore, BOPP films prepared by melt extrusion and the biaxial stretching of PP show high efficiency. However, due to the intrinsic low permittivity of PP, the BOPP usually exhibits a low energy density $\left(<2 \mathrm{~J} / \mathrm{cm}^{3}\right)$ [28]. In addition, the working temperature of BOPP is usually below $105^{\circ} \mathrm{C}$, which significantly limits its application in high-temperature environments $[37,38]$.

\subsubsection{Polyimide (PI)}

In addition to BOPP, PI is another important linear dielectric polymer. The thermal stability of PI $\left(>500{ }^{\circ} \mathrm{C}\right)$ is much higher than that of BOPP $\left(<105^{\circ} \mathrm{C}\right)$, which is mainly due to the imide structure in its main chain. In addition, PI also exhibits good mechanical and chemical resistance, as well as excellent dielectric properties, as summarized in Table 1 [38,39]. Therefore, several kinds of commercial PIs, such as Kapton (developed by DuPont) and UPILEX (developed by UBE), have been developed for high-performance dielectric capacitors. However, the conduction loss of PI rapidly increases with increasing temperature. Specifically, at $150{ }^{\circ} \mathrm{C}$, the conduction loss of Kapton under $200 \mathrm{MV} / \mathrm{m}$ is as high as $24 \%$ (i.e., the efficiency is only $76 \%$ ), and the conduction loss further increases to almost $100 \%$ at $250{ }^{\circ} \mathrm{C}$ [40].

\subsubsection{PEI}

PEI is an amorphous engineering thermoplastic dielectric polymer, with similar dielectric properties to those of PI. Compared with PI, the molecular chain of PEI has flexible ether linkages, improving the processability of PEI. However, PEI exhibits poor thermal stability compared to PI [38]. For example, ULTEM (developed by SABIC) is one of the most important commercial PEI products but its glass transition temperature $\left(T_{\mathrm{g}}\right)$ ranges from $217^{\circ} \mathrm{C}$ to $247^{\circ} \mathrm{C}$, much lower than that of Kapton or UPILEX. However, compared with PI, PEI exhibits better energy storage performance under high temperatures (up to $200{ }^{\circ} \mathrm{C}$ ). For instance, at $150^{\circ} \mathrm{C}$, PEI has an efficiency of up to $90 \%$ under $200 \mathrm{MV} / \mathrm{m}$. The efficiency of PEI still approaches $80 \%$ at $200{ }^{\circ} \mathrm{C}$, exhibiting much better high-temperature energy storage performance than PI [41]. 
Table 1. Summary of basic properties of several linear dielectric polymers.

\begin{tabular}{ccccc}
\hline Polymer & $\begin{array}{c}\text { Max Operating } \\
\text { Temperature } \\
\left({ }^{\circ} \mathbf{C}\right)\end{array}$ & $\begin{array}{c}\text { Permittivity } \\
\text { (at 1 kHz) }\end{array}$ & $\begin{array}{c}\text { Dissipation Factor } \\
\text { (at 1 kHz) } \mathbf{\%})\end{array}$ & $\begin{array}{c}\text { Breakdown Strength } \\
\text { (MV/m) }\end{array}$ \\
\hline BOPP & 105 & 2.2 & $<0.02$ & $449-555(3-5 \mu \mathrm{m})$ \\
\hline PI (Kapton) & $360-410$ & $2.7-3.5$ & $0.13-0.26$ & $154-303(7.6-127 \mu \mathrm{m})$ \\
\hline PI (UPILEX) & $285-500$ & $3.2-3.5$ & $0.13-0.7$ & $147-320(12.5-125 \mu \mathrm{m})$ \\
\hline PEI (ULTEM) & $217-247$ & 3.15 & 0.12 & $200(25 \mu \mathrm{m})$ \\
\hline LDPE & $95-113$ & 3 & $<0.05$ & $200(30 \mu \mathrm{m})$ \\
\hline PEEU & 250 & 4.7 & $<1$ & $600(2-3 \mu \mathrm{m})$ \\
\hline PMMA & 150 & 3.3 & $<5$ & $550(13-24 \mu \mathrm{m})$ \\
\hline PET & 125 & 3.3 & $<0.5$ & $570(3 \mu \mathrm{m})$ \\
\hline PC & 125 & 2.9 & $<0.2$ & $550(0-13 \mu \mathrm{m})$ \\
\hline
\end{tabular}

\subsubsection{Other Linear Dielectric Polymers}

In addition to BOPP, PI, and PEI, many other polymers, such as low-density polyethylene (LDPE) [42], poly (arylene ether urea) (PEEU) [43], polymethyl methacrylate (PMMA) [44], polyethylene terephthalate (PET) [37], and polycarbonate (PC) are also linear dielectric polymers [45]. Table 1 summarizes some of the basic properties of these linear dielectric polymers.

\subsection{Linear Dielectric Polymer Blends}

Although the low permittivity of linear dielectrics usually limits an increase in their energy density, their clear superiority in charge-discharge efficiency compared to other dielectric materials has attracted an increasing amount of attention. To date, several reports dedicated to increasing the energy density of linear dielectrics have been published [46-49]. Most of these reports mainly focus on improving the permittivity or breakdown strength of dielectrics by molecular structure design or component regulation.

As is well known, the dielectric breakdown strength of polymers is closely related to the weak points in dielectric materials. Generally, the free volume between molecular chains, physical voids, and disordered structures in materials are all dielectric defects [50-52]. Therefore, it is necessary to minimize these micro- and macrostructural defects in dielectric materials. Based on this analysis, researchers have effectively reduced the microstructural defects in polymers by reducing the free volume between molecular chains [53]. In brief, PI/PEI composite films with reduced weak points were obtained by a feasible blending strategy.

Figure 4a presents the schematic chemical structure of PI, which shows two positively charged phenyls. In contrast, the molecular chain of PEI exhibits significant electronegativity, as shown in Figure $4 \mathrm{~b}$. Therefore, the packing density and defects of molecular chains can be controlled by adjusting the ratio of PI/PEI ( $w t \% / w t \%)$. Figure $4 \mathrm{c}$ presents the average interchain spacing of PI/PEI dielectric films as a function of PEI content [53]. The results showed that PI/PEI blends, with a ratio of 50/50, exhibited the smallest interchain spacing, 10\% lower than that of unadulterated PI or PEI. Similarly, Zhang et al. calculated the change in the specific heat capacity of blended films with varying PEI content during glass transition (Figure 4d), and their results were consistent with those of Figure 4a. Thus, PI/PEI blended films with 50\% PEI content exhibited the most extended polymer chains among all the reported samples [54-57]. Furthermore, PI/PEI blend films with $50 \%$ PEI content also exhibited a higher density $\left(1.35 \mathrm{~g} / \mathrm{cm}^{3}\right)$ compared to both pure PI film $\left(1.3 \mathrm{~g} / \mathrm{cm}^{3}\right)$ and pure PEI film $\left(1.27 \mathrm{~g} / \mathrm{cm}^{3}\right)$. Meanwhile, the thermal conductivity and storage modulus values of PI/PEI blended films with 50\% PEI content were also higher than the values of PI and PEI (Figure 4e,f). In conclusion, this article presented a general strategy to reduce the weak points, such as voids and free volume in polymers by 
exploiting interchain electrostatic forces in polymer blends. The reduced weak points could be attributed to the dense chain packing in the blend polymers. Therefore, modifying the polymer molecular chain to reduce structural defects is an important method to improve the breakdown strength of linear polymers.

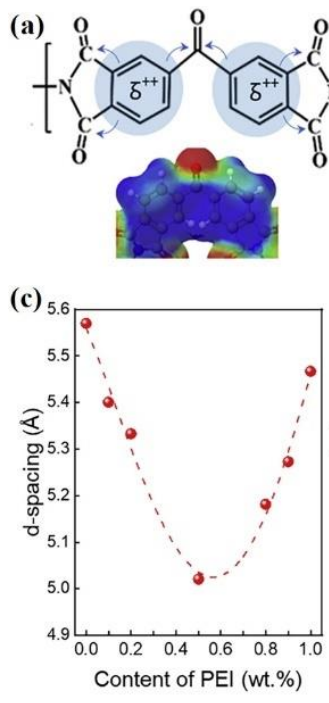

(g)

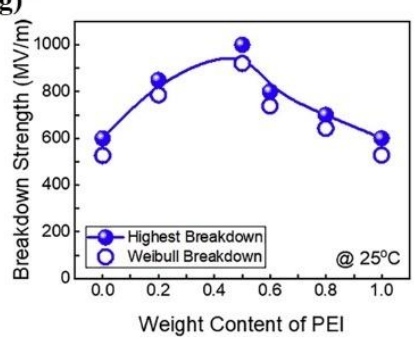

(b)

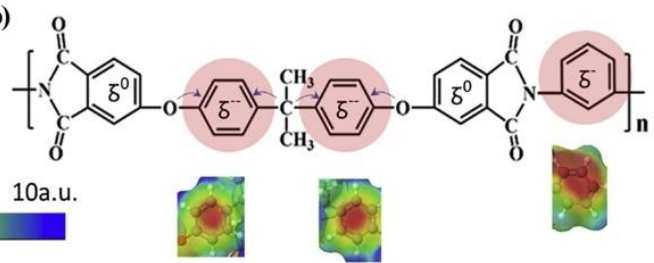

(e)

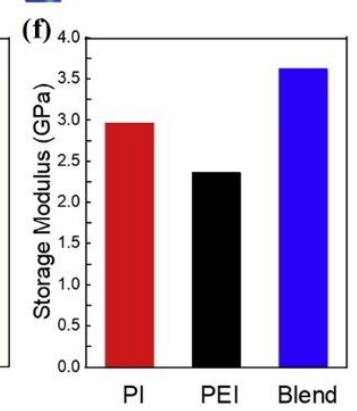

(h)
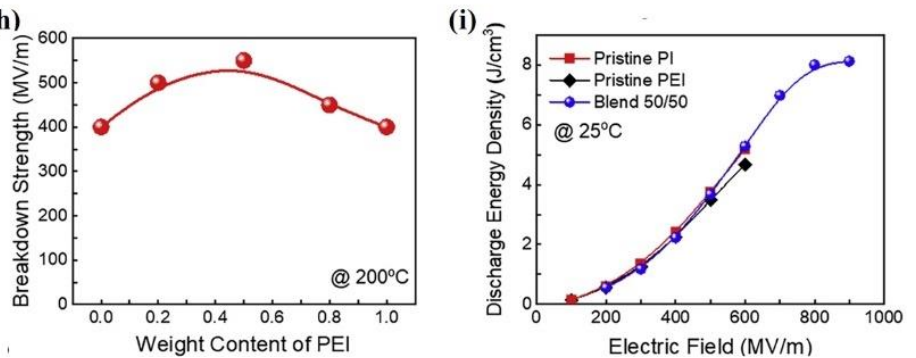

Figure 4. Schematic chemical structures of PI (a) and PEI (b). (c,d) Average interchain spacing (c) and the change in specific heat capacity during glass transition $\left(\Delta C_{p}\right)(\mathbf{d})$ for PI/PEI blends with different ratios. (e,f) Thermal conductivity (e) and storage modulus (f) of pristine PI, PEI, and PI/PEI blend with a 50/50 ratio. (g,h) Dielectric breakdown strength as a function of the PI/PEI blend ratio at room temperature (g) and at $200{ }^{\circ} \mathrm{C}(\mathrm{h})$. (i) Discharge energy density of PI/PEI blend films under various electric fields at room temperature. Reproduced with permission from Ref. [53]. Copyright 2021, Elsevier.

The micro-structured weak points in PI/PEI blended films decrease in number due to the reduced interchain spacing, significantly improving their breakdown strength. Figure $4 \mathrm{~g}$ presents the breakdown strength of various PI/PEI blended films at room temperature. As can be seen, PI/PEI films with 50\% PEI content exhibit the highest breakdown strength of $1000 \mathrm{MV} / \mathrm{m}$, while the value for PI and PEI films is only $600 \mathrm{MV} / \mathrm{m}$. Even at $200{ }^{\circ} \mathrm{C}$, the breakdown strength of blended films with $50 \%$ PEI can still be maintained at $550 \mathrm{MV} / \mathrm{m}, 35 \%$ higher than the pure PI or PEI films ( $400 \mathrm{MV} / \mathrm{m}$ ) (Figure $4 \mathrm{~h}$ ). Consequently, the energy density of a PI/PEI blended film with $50 \%$ PEI is $8 \mathrm{~J} / \mathrm{cm}^{3}$, while the energy densities of pure PI and PEI films are below $5 \mathrm{~J} / \mathrm{cm}^{3}$ (Figure $4 \mathrm{i}$ ). In addition to PEI, poly(1,4-phenylene ether-sulfone) (PSU) containing the same negatively charged group in its polymer chain was combined with PI. The breakdown strength and energy density of the PI/PSU blended films also show significant improvement compared to that of the PI or PSU films. Therefore, reducing the weak points in dielectric polymers is an effective strategy for enhancing the breakdown strength of dielectric polymers.

Introducing polymers with high dielectric constants into linear dielectric polymers has been shown to be effective for improving their energy storage performance. As can be seen from Table 1, PEEU exhibits higher permittivity (4.7) and breakdown strength $(600 \mathrm{MV} / \mathrm{m})[58,59]$. Thus, PEEU has attracted an increasing amount of attention. However, 
the poor flexibility caused by the small molecular weight of PEEU greatly hinders its practical application. To solve this problem, PEEU was introduced into the PI matrix as an "organic filler". As a result, PEEU/PI composite films with good flexibility and high energy storage performance have been fabricated [60].

Figure 5a presents the synthesis process for obtaining PEEU/PI blended films. By adjusting the proportion of PEEU and PI, PEEU/PI blended films with ratios of 5/95, $10 / 90,15 / 85,20 / 80$, and $25 / 75$ were obtained. Figure $5 \mathrm{~b}$ shows the dielectric constants of PEEU/PI blended films with varying PEEU content. The dielectric constant of the blended films increases with increasing PEEU content in these composite films. In particular, the dielectric constant of the $25 / 75$ PEEU/PI blended film is 5.02, about $17 \%$ higher than that of pristine PI (4.28). Meanwhile, all the PEEU/PI blended films exhibit a relatively low dissipation factor during the tested frequency range (Figure $5 \mathrm{c}$ ).
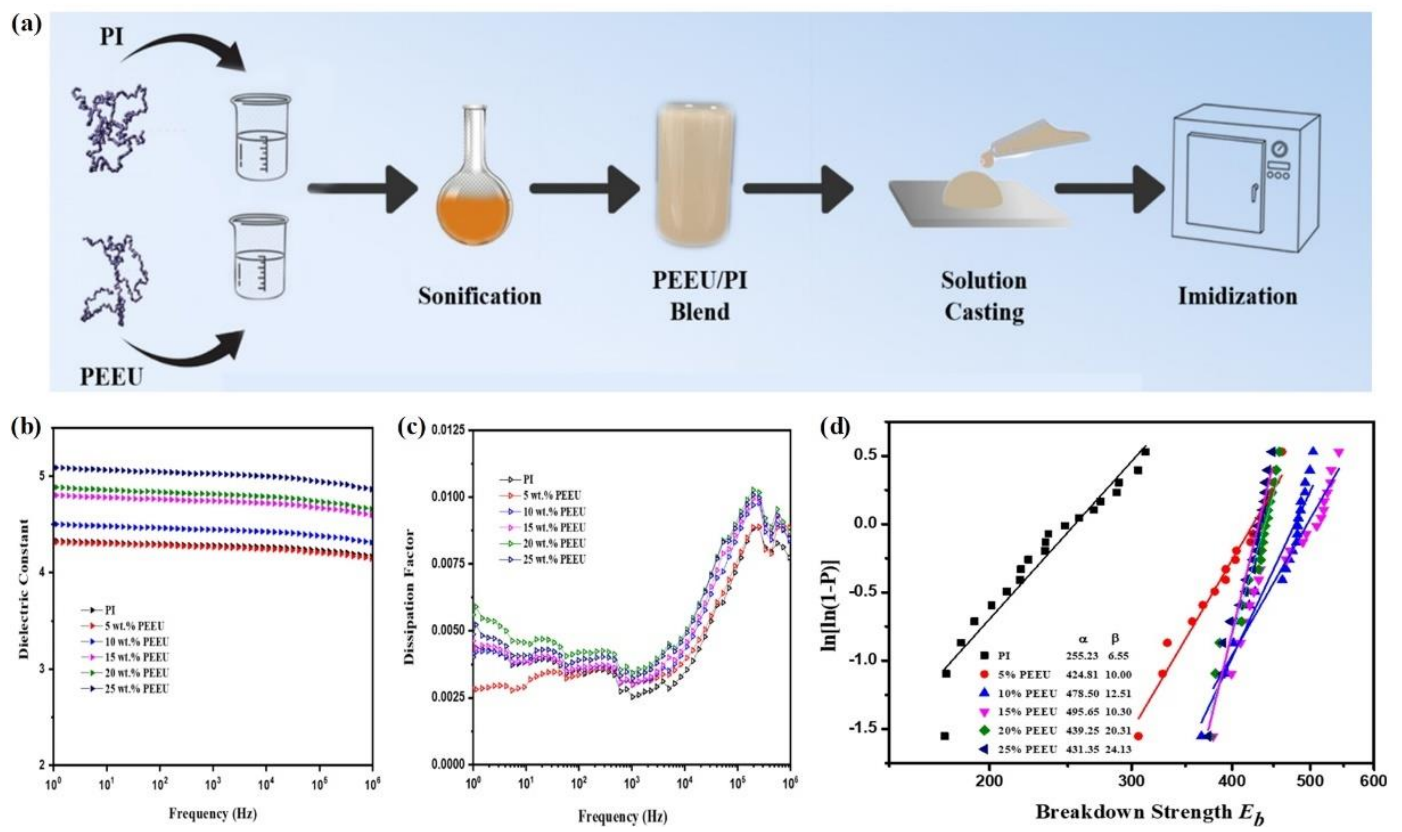

Figure 5. (a) Schematics of the synthesis process of PEEU/PI blend films. (b,c) The dielectric constant (b) and dissipation factor (c) of PEEU/PI blend films with various ratios as a function of frequency at ambient temperature. (d) Weibull breakdown strength of PI and PEEU/PI blend films at ambient temperature (measured at $10^{3} \mathrm{~Hz}$ ). Reproduced with permission from Ref. [60]. Copyright 2017, Wiley-VCH.

Figure $5 \mathrm{~d}$ presents the Weibull breakdown strength values of PEEU/PI blended films. The shape parameter $(\beta)$ values of all the blended films (ranging from 10.00 to 24.13) are higher than that of the PI film (6.55). Meanwhile, the breakdown strength values of all the PEEU/PI blended films are higher than that of the PI film. In particular, the 15/85 PEEU/PI blended film exhibits a breakdown strength of $495.65 \mathrm{MV} / \mathrm{m}$, almost twice that of pristine PI $(255.23 \mathrm{MV} / \mathrm{m})$. Due to the increased breakdown strength and enhanced dielectric constant, the energy density of the $15 / 85$ PEEU/PI film $\left(5.14 \mathrm{~J} / \mathrm{cm}^{3}\right)$ is more than four times higher than that of PI $\left(1.23 \mathrm{~J} / \mathrm{cm}^{3}\right)$.

\subsection{Ferroelectric/Linear Dielectric Polymer Blends}

Compared with linear dielectric polymers, ferroelectric polymers usually exhibit higher energy densities due to their higher permittivity [61,62]. For example, the permittivity of poly(vinylidene fluoride-trifluoroethylene-chlorofluoroethylene) (P(VDF-TrFE-CFE)) is about 50. However, ferroelectric polymers such as PVDF, PVDF copolymers, and PFDF terpolymers often exhibit high dissipation factors (0.02), leading to low charge-discharge efficiency. Recently, blended films prepared with a linear dielectric polymer matrix and high 
permittivity ferroelectric polymers have attracted global attention, due to their potential for improving the dielectric constant of blended films without sacrificing breakdown strength.

Zhou et al. significantly improved the energy storage performance of pure polyurea (PUA) film by incorporating (P(VDF-TrFE-CFE)) into a PUA matrix [63]. By adjusting the content of $\mathrm{P}(\mathrm{VDF}-\mathrm{TrFE}-\mathrm{CFE})$ in the $\mathrm{P}(\mathrm{VDF}-\mathrm{TrFE}-\mathrm{CFE}) / \mathrm{PUA}$ blended solution, various $\mathrm{P}(\mathrm{VDF}-\mathrm{TrFE}-\mathrm{CFE})$ /PUA composite films were obtained. Figure 6a presents the dielectric properties of pure PUA film and various blended films, where P10 represents the composite film with 10 vol \% P(VDF-TrFE-CFE). Due to the high dielectric constant of P(VDF-TrFECFE), the blended film with 30 vol \% P(VDF-TrFE-CFE) exhibits the highest dielectric constant of 5.3 at $10^{3} \mathrm{~Hz}$. Meanwhile, the dielectric loss shows a slightly increasing tendency with increasing P(VDF-TrFE-CFE) content. Zhou et al. further calculated the breakdown strength of pristine PUA and various blended films, as shown in Figure $6 \mathrm{~b}$. Compared with the breakdown strength of pristine PUA film $(4930 \mathrm{kV} / \mathrm{cm})$, the value of $\mathrm{P} 10$ is $5130 \mathrm{kV} / \mathrm{cm}$. However, for blended films with 20 and $30 \mathrm{vol} \% \mathrm{P}$ (VDF-TrFE-CFE), the breakdown strength significantly decreases to $4750 \mathrm{kV} / \mathrm{cm}$ and $4320 \mathrm{kV} / \mathrm{cm}$.

(a)

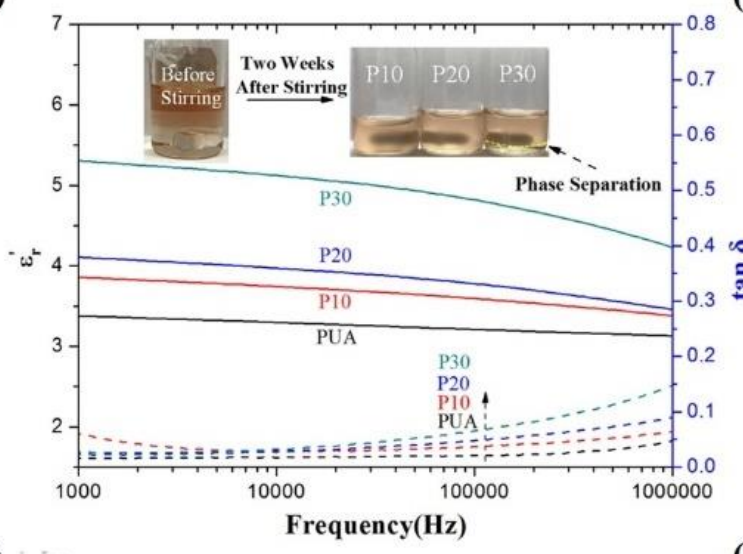

(c)

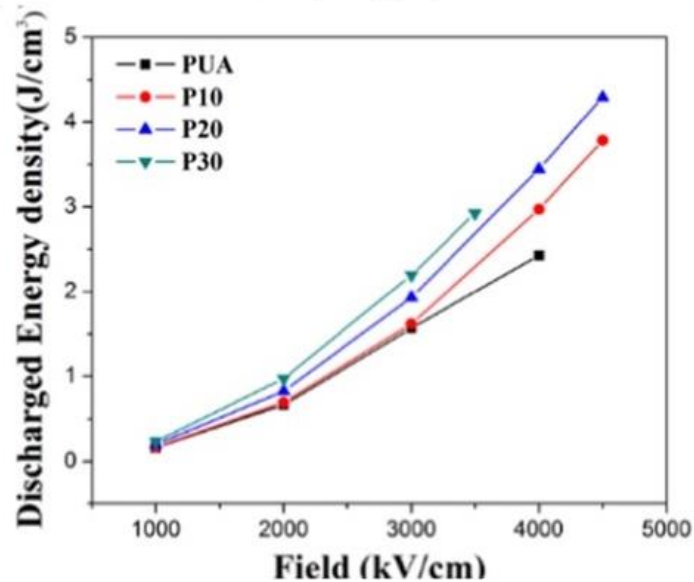

(b)

(d)
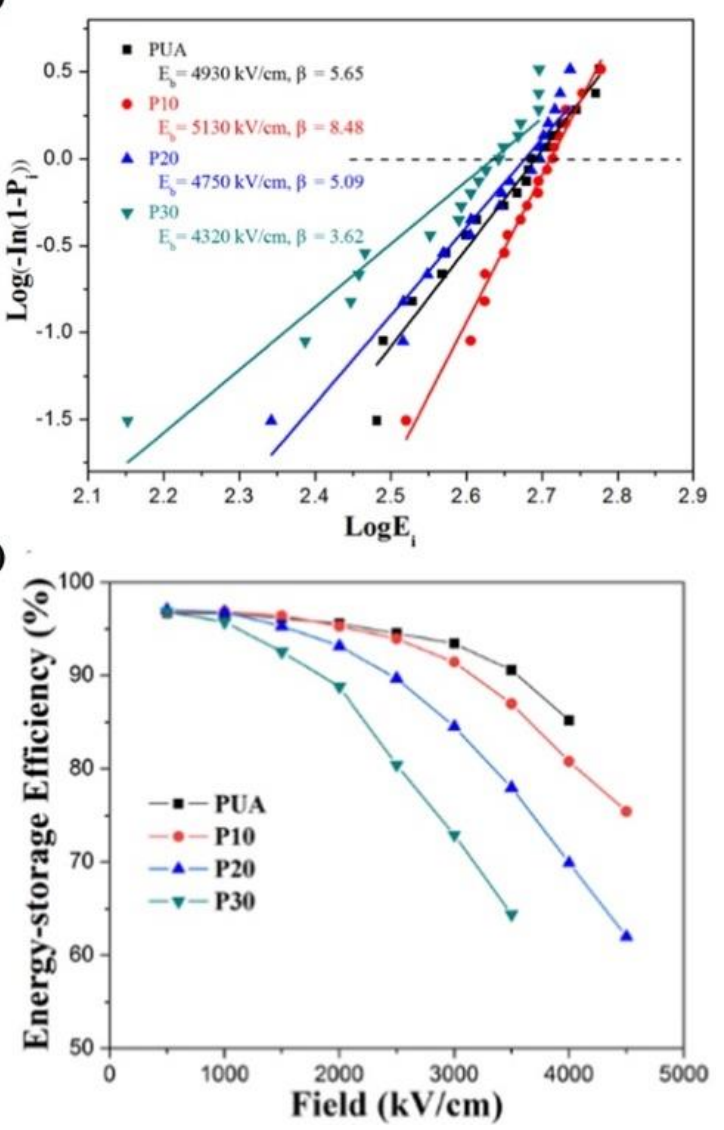

Figure 6. Dielectric constant (a), breakdown strength (b), discharged energy density (c) and energy-storage efficiency of PUA and PUA/P(VDF-TrFE-CFE) blend films (d) at ambient temperature. The breakdown strength was tested under a voltage ramp of $0.1 \mathrm{kV} \mathrm{s}^{-1}$, and the P-E hysteresis loops were tested at $10 \mathrm{~Hz}$. Reproduced with permission from Ref. [63]. Copyright 2019, IOP.

Figure $6 c, d$ presents the energy storage performance of PUA and various blended films. On the one hand, due to the enhancement of the dielectric constant by P(VDF-TrFECFE), the energy density of the blended films increases with increasing P(VDF-TrFE-CFE) content under the same electric field (Figure 6c). On the other hand, the introduction of $\mathrm{P}(\mathrm{VDF}-\mathrm{TrFE}-\mathrm{CFE})$ has a negative influence on the charge-discharge efficiency of the $\mathrm{P}(\mathrm{VDF}-\mathrm{TrFE}-\mathrm{CFE}) / \mathrm{PUA}$ films, which is mainly due to its high conduction loss. 
Therefore, $\mathrm{P}(\mathrm{VDF}-\mathrm{TrFE}-\mathrm{CFE})$ is beneficial for improving the dielectric constant of blended films. Consequently, the energy density of P(VDF-TrFE-CFE) blended films significantly improves with increasing P(VDF-TrFE-CFE) content under the same electric field (Figure 6c). However, the ferroelectric properties and high field conduction loss of $\mathrm{P}(\mathrm{VDF}-\mathrm{TrFE}-\mathrm{CFE})$ negatively affect the efficiency of these composite films (Figure 6d). As a result, the discharge energy density of the P20 composite film is $4.3 \mathrm{~J} / \mathrm{cm}^{3}$, while that of pristine PUA is only $2.43 \mathrm{~J} / \mathrm{cm}^{3}$. Overall, introducing ferroelectric polymers with high permittivity as a functional filler into a linear dielectric polymer matrix has proven to be beneficial for improving the energy-storage performance of linear dielectric polymers.

\section{Linear Polymer Nanocomposites}

\subsection{The OD Nanoparticle/Linear Polymer Nanocomposites \\ 3.1.1. Nanoparticles with High Permittivity}

In the past decades, many studies dedicated to improving the energy storage properties of linear dielectrics have been reported. Among these, polymer nanocomposite film, which is usually composed of polymer matrix and a nanofiller, has attracted an increasing amount of attention [32,64]. As the second phase of these nanocomposite films, the intrinsic features of the nanofiller, including dielectric constant, shape, size, and concentration, have a great effect on the energy storage performance of these materials. In addition, the polymer/filler interface and the spatial composite structure of the polymer nanocomposites are also highly significant [65-67]. Ceramic dielectrics, such as $\mathrm{BaTiO}_{3}$ (BTO), $\mathrm{TiO}_{2}$, and $\left(\mathrm{Ba}_{x} \mathrm{Sr}_{1-\mathrm{x}}\right) \mathrm{TiO}_{3}$, usually have much higher dielectric constants than polymers [68-70]. Therefore, incorporating ceramic nanofillers as functional materials into linear polymers is a good strategy for fabricating polymer nanocomposites with improved energy storage performance.

Sun et al. fabricated BTO/PI nanocomposites with good energy storage performance by incorporating BTO nanoparticles into PI [71]. Figure 7a presents the dielectric constants of BTO/PI nanocomposites as a function of BTO content at room temperature. The results show that the dielectric constant of a nanocomposite with 9 vol \% BTO is about 6.8 , more than twice that of pure PI ( 3.1). This dielectric constant enhancement can be attributed to the following reasons. Firstly, the introduction of BTO nanoparticles with a high dielectric constant increases the permanent dipoles in the nanocomposites. Secondly, the large quantity of interfacial boundaries between the BTO nanoparticles and the PI matrix significantly promotes interfacial polarization in the nanocomposites. As is consistent with the pure PI film, the dielectric loss of all the BTO/PI nanocomposites is almost unchanged in the tested frequency $\left(10^{3}\right.$ to $10^{6} \mathrm{~Hz}$ ) (Figure $7 \mathrm{~b}$ ).

Figure 7c summarizes the breakdown strength of PI and various BTO/PI nanocomposites under different temperatures, varying from $25^{\circ} \mathrm{C}$ to $200{ }^{\circ} \mathrm{C}$. The results show that the introduction of BTO nanoparticles has a negative influence on the breakdown strength of the nanocomposites. For instance, the breakdown strength of pure PI film at room temperature is about $450 \mathrm{kV} / \mathrm{mm}$, while the corresponding value for BTO/PI composite film with $9 \mathrm{vol} \%$ BTO is only about $150 \mathrm{kV} / \mathrm{mm}$. The significant difference in the permittivity between the nanofiller (BTO nanoparticle) and polymer matrix (PI) may account for the sharp decrease in the breakdown strength of the composite films. Moreover, the structural imperfections induced by the introduction of the nanofiller may also contribute to the decreasing breakdown strength. Due to the sharply decreased breakdown strength, the discharge energy density values of the BTO/PI composite films are lower than that of pure PI (Figure 7d). Therefore, although the introduction of BTO can effectively enhance the permittivity of the composite films, their energy density is not improved. In general, the introduction of nanofillers with high dielectric constants can effectively improve the dielectric constant of composite materials, but this does not improve their energy density. Therefore, to obtain polymer nanocomposites with improved energy density, other factors should be considered, particularly polymer/filler interface compatibility. 
(a)

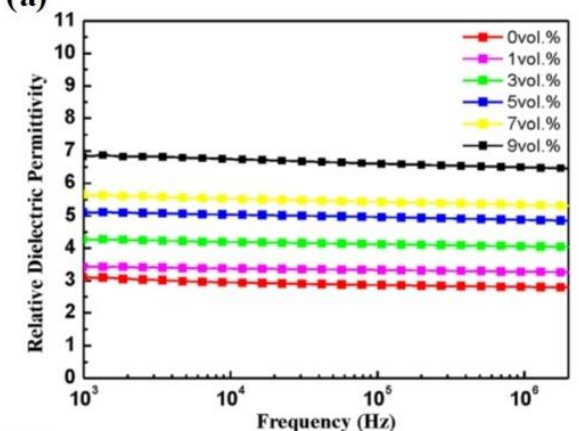

(c)

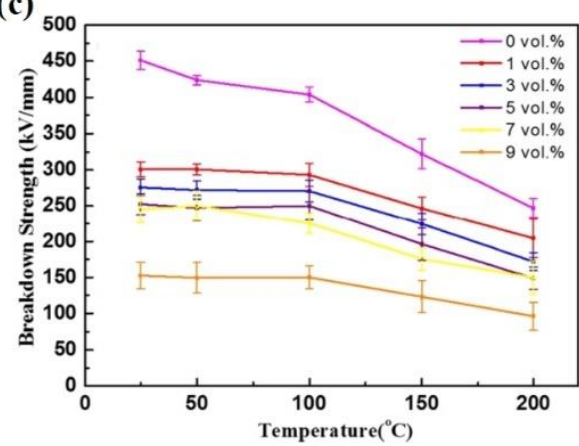

(b)

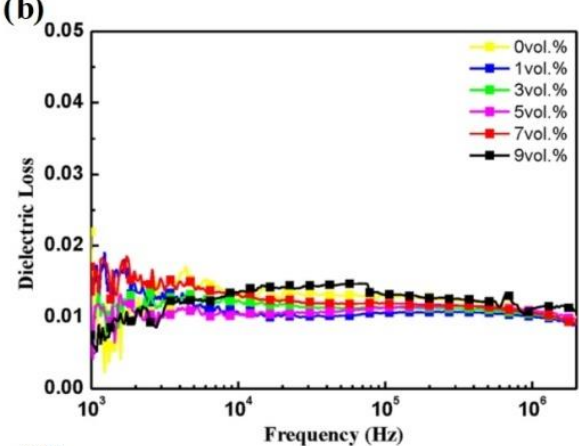

(d)

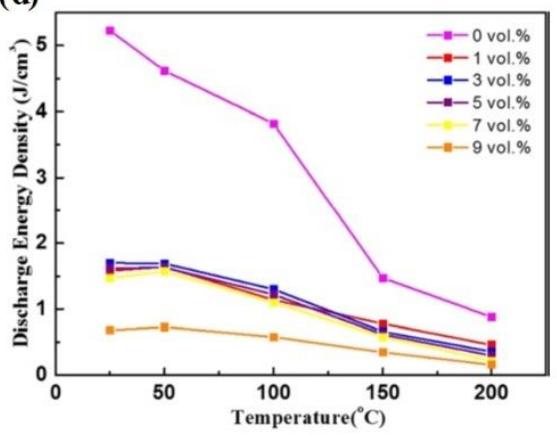

Figure 7. The relative dielectric permittivity (a) and dielectric loss (b) of BTO/PI nanocomposites with a BTO content of $0,1,3,5,7$, and $9 \mathrm{vol} \%$ at ambient temperature. Dependences of breakdown strength (c) and discharge energy density (d) for pure PI and BTO/PI nanocomposites with BTO content of $1,3,5,7$, and $9 \mathrm{vol} \%$ on temperature ranging from $25^{\circ} \mathrm{C}$ to $200{ }^{\circ} \mathrm{C}$ at $100 \mathrm{~Hz}$. Reproduced with permission from Ref. [71]. Copyright 2017, American Institute of Physics.

\subsubsection{Surface-Modified High Permittivity Nanoparticles}

As discussed above, the polymer/filler interface could significantly influence the dielectric performance of the composites. Generally, surface modification involves grafting suitable ligands onto the surface of the particles to prevent them from agglomerating and make them compatible with other phases. Therefore, surface modification is an effective method to overcome interfacial energy barriers and reduce nanofiller agglomeration in composite films [72]. To date, various modifiers have been reported to improve the polymer/filler interface compatibility, and this strategy has been shown to effectively improve the energy storage performance of polymer nanocomposites. Dang et al. modified the surface of BTO nanoparticles with a silane coupling agent (KH550) and combined the modified BTO nanoparticles with a PVDF matrix, significantly improving the interface compatibility between the BTO and PVDF [73]. Zhou et al. prepared surface hydroxylated BTO nanoparticles (h-BTO) by dispersing BTO in an aqueous solution of $\mathrm{H}_{2} \mathrm{O}_{2}$, showing that h-BTO/PVDF nanocomposites exhibit improved breakdown strength compared to that of unmodified-BTO/PVDF nanocomposites [74]. Yu et al. reported polyvinylpyrrolidonemodified BTO/PVDF nanocomposite films with an improved dielectric constant (77) and enhanced electric breakdown strength $(336 \mathrm{MV} / \mathrm{m})$. The energy density of their polyvinylpyrrolidone-modified BTO/PVDF nanocomposite is $6.8 \mathrm{~J} / \mathrm{cm}^{3}$ [75].

\subsubsection{Wide Bandgap Nanoparticles}

Although the surface modification of nanofillers is beneficial for improving the energy density of nanofiller/polymer nanocomposites, complicated and time-wasting preparation processes often limit their industrial application. Recently, several new nanofillers with relatively low permittivity but wide bandgaps have been incorporated with polymer matrices without surface modification and the reported results show that these composites exhibit high energy storage performance. Fan et al. fabricated $\mathrm{Al}_{2} \mathrm{O}_{3}$ nanoparticle/PEI nanocomposite films by simply casting a mixed precursor solution on a glass plate, as 
shown in Figure 8a. The energy storage properties of blended films as a function of $\mathrm{Al}_{2} \mathrm{O}_{3}$ content at various temperatures were also studied [76].
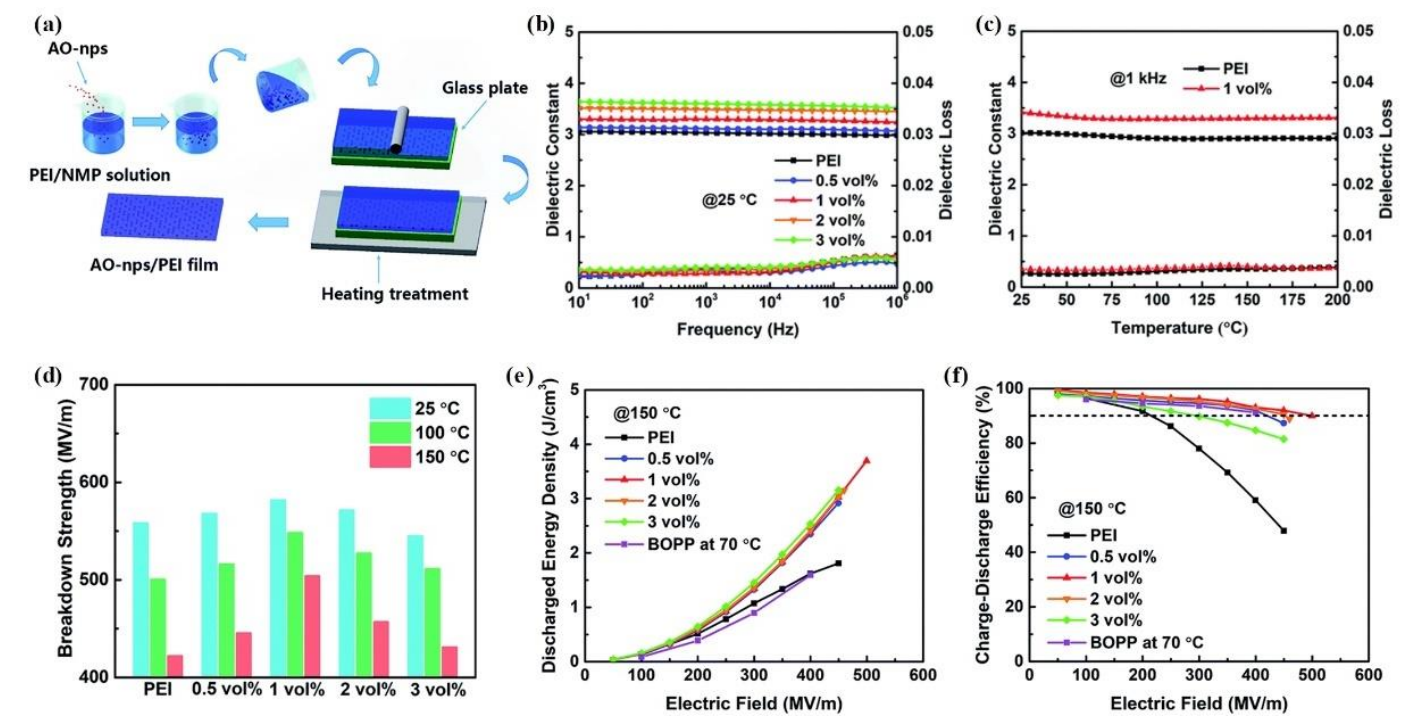

Figure 8. (a) Schematic illustration of the fabrication of the $\mathrm{Al}_{2} \mathrm{O}_{3} / \mathrm{PEI}$ nanocomposites. (b) The frequency-dependent dielectric constant of pristine PEI and $\mathrm{Al}_{2} \mathrm{O}_{3} / \mathrm{PEI}$ nanocomposites at $25^{\circ} \mathrm{C}$. (c) Temperature-dependent dielectric constant and loss of pristine PEI and $1 \mathrm{vol} \% \mathrm{Al}_{2} \mathrm{O}_{3} / \mathrm{PEI}$ nanocomposite at $1 \mathrm{kHz}$. (d) Breakdown strength of pristine PEI and $\mathrm{Al}_{2} \mathrm{O}_{3} /$ PEI nanocomposites at $25^{\circ} \mathrm{C}, 100{ }^{\circ} \mathrm{C}$, and $150{ }^{\circ} \mathrm{C}$. (e,f) Discharge energy density and efficiency of pure PEI and $\mathrm{Al}_{2} \mathrm{O}_{3} / \mathrm{PEI}$ nanocomposites at $150{ }^{\circ} \mathrm{C}$. Reproduced with permission from Ref. [76]. Copyright 2020, The Royal Society of Chemistry.

Figure $8 \mathrm{~b}$ shows the dielectric constant and dielectric loss of $\mathrm{Al}_{2} \mathrm{O}_{3} / \mathrm{PEI}$ blended films with varying $\mathrm{Al}_{2} \mathrm{O}_{3}$ volume content. Compared with the PEI film, the dielectric constant of the $\mathrm{Al}_{2} \mathrm{O}_{3} / \mathrm{PEI}$ nanocomposites slightly increases from 3.11 to 3.6 when the volume percentage of $\mathrm{Al}_{2} \mathrm{O}_{3}$ increases from $0.5 \%$ to $3 \%$. Meanwhile, the dielectric loss of all the nanocomposites remains below 0.005 over the tested frequency. Moreover, the dielectric properties of the $\mathrm{Al}_{2} \mathrm{O}_{3} / \mathrm{PEI}$ nanocomposite with $1 \mathrm{vol} \% \mathrm{Al}_{2} \mathrm{O}_{3}$ remain stable across the tested temperature range $\left(25^{\circ} \mathrm{C}\right.$ to $\left.200{ }^{\circ} \mathrm{C}\right)$, indicating that the $\mathrm{Al}_{2} \mathrm{O}_{3} / \mathrm{PEI}$ nanocomposites exhibit high thermal stability (Figure 8c).

Figure $8 \mathrm{~d}$ presents the breakdown strength of various $\mathrm{Al}_{2} \mathrm{O}_{3} / \mathrm{PEI}$ nanocomposites at different temperatures. The breakdown strength of these $\mathrm{Al}_{2} \mathrm{O}_{3} / \mathrm{PEI}$ nanocomposites increases with increasing $\mathrm{Al}_{2} \mathrm{O}_{3}$ content from 0 to $1 \mathrm{vol} \%$ at temperatures up to $150{ }^{\circ} \mathrm{C}$. However, when the $\mathrm{Al}_{2} \mathrm{O}_{3}$ content increases to $2 \mathrm{vol} \%$ and $3 \mathrm{vol} \%$, the breakdown strength then decreases. This is potentially due to the weak points caused by the aggregation of $\mathrm{Al}_{2} \mathrm{O}_{3}$ nanoparticles. Moreover, due to the high thermal stability of the $\mathrm{Al}_{2} \mathrm{O}_{3} / \mathrm{PEI}$ composites, the breakdown strengths of the $\mathrm{Al}_{2} \mathrm{O}_{3} / \mathrm{PEI}$ composites only exhibit a slight decrease with increasing temperature. For the composite film with $1 \mathrm{vol} \% \mathrm{Al}_{2} \mathrm{O}_{3}$, the breakdown strength at $150{ }^{\circ} \mathrm{C}$ is only about $13 \%$ lower than that at $25^{\circ} \mathrm{C}$. However, the breakdown strength values of the PEI films at $150{ }^{\circ} \mathrm{C}$ are $24 \%$ lower than those at $25^{\circ} \mathrm{C}$. Due to their enhanced dielectric constants, the significantly increased breakdown strength, and the high-temperature stability, the energy storage performance of the $\mathrm{Al}_{2} \mathrm{O}_{3} / \mathrm{PEI}$ nanocomposites at $150{ }^{\circ} \mathrm{C}$ is significantly improved compared with the corresponding PEI film values (Figure 8e,f). Specifically, the recoverable energy density and efficiency of the $1 \mathrm{vol} \% \mathrm{Al}_{2} \mathrm{O}_{3} / \mathrm{PEI}$ nanocomposite at $150{ }^{\circ} \mathrm{C}$ are $3.7 \mathrm{~J} / \mathrm{cm}^{3}$ and $90.1 \%$, respectively, while the corresponding values of the PEI film are only $1.81 \mathrm{~J} / \mathrm{cm}^{3}$ and $47.9 \%$, respectively. 


\subsection{The $1 D$ Nanofiber/Linear Polymer Nanocomposites}

In addition to 0D nanoparticles, 1D nanomaterials (such as nanorods, nanofibers, and nanowires) are also used as composite materials with polymer matrices to enhance the energy storage properties of linear dielectric polymers. Compared with nanoparticles, 1D nanomaterials can significantly improve the breakdown strength of polymer composites, mainly due to their high aspect ratio and small specific surface area [24,77]. Hu et al. fabricated $\mathrm{BaTiO}_{3}$ nanofibers (BTNFs) by electrospinning and then compounded the nanofibers with a PI matrix to prepare BTNFs /PI nanocomposites with varying BTNF volume content [78]. As shown in Figure 9a, with the BTNF content increasing from 0 to $9 \mathrm{vol} \%$, the permittivity of the BTNFs/PI nanocomposites significantly increases from 3.1 to 8.3 at $1 \mathrm{kHz}$. This is mainly due to the high permittivity of the BTNFs. Meanwhile, the dielectric loss of the BTNFs/PI nanocomposites slightly increases with increasing BTNF content, although the dielectric loss of all the nanocomposites is below 0.04 (Figure 9b).
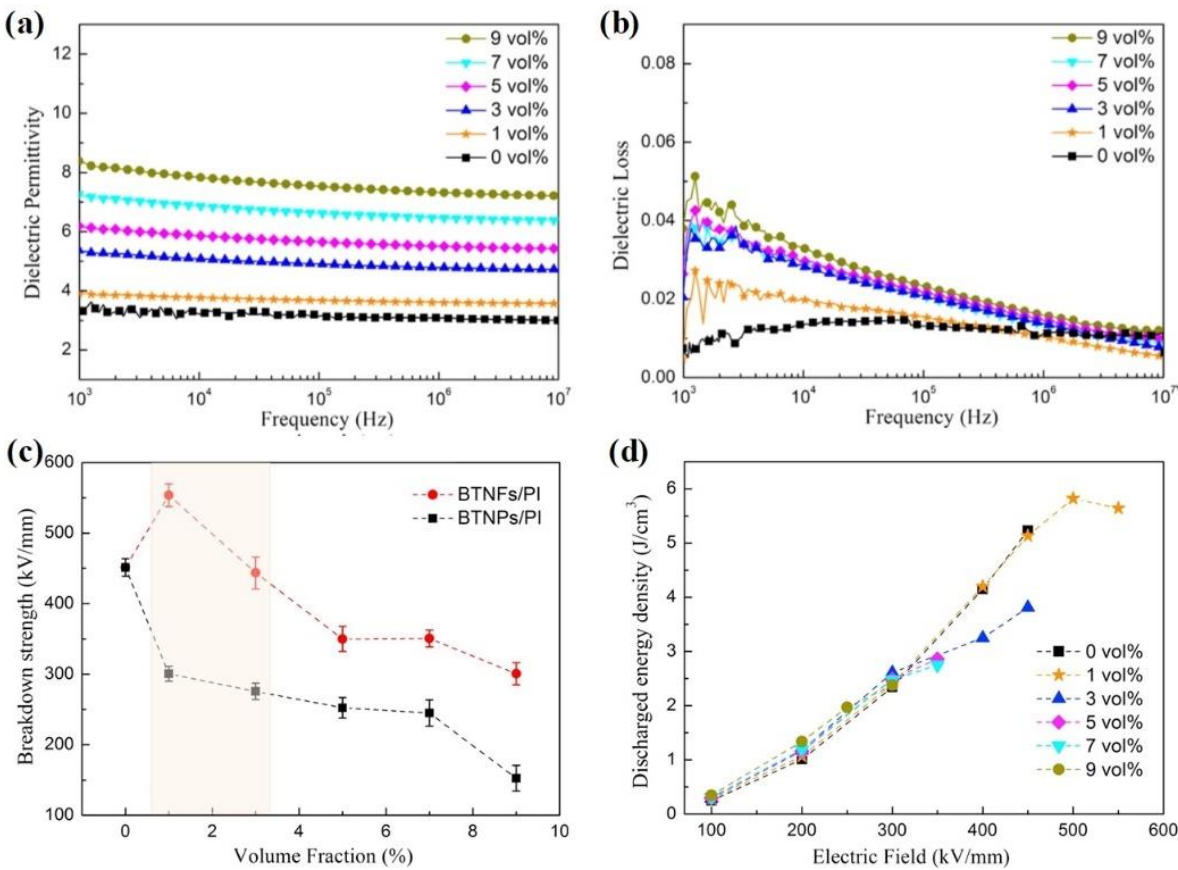

Figure 9. Frequency-dependency of dielectric permittivity (a) and dielectric loss (b) of BTNFs/PI nanocomposites. (c) Breakdown strength of BTNFs/PI and BTNPs/PI nanocomposites as a function of content loading. (d) Discharged energy density of BTNFs/PI nanocomposites as a function of the electric field. Reproduced with permission from Ref. [78]. Copyright 2018, Elsevier.

Figure 9c shows the breakdown strengths of BTNFs/PI nanocomposites and composites made with BT nanoparticles (BTNPs). The breakdown strength of the BTNFs/PI composite films is higher than the value of BTNPs/PI nanocomposites at the same nanofiller volume content. Specifically, the $1 \mathrm{vol} \%$ BTNFs/PI nanocomposite exhibits a high breakdown strength of is $553 \mathrm{kV} / \mathrm{mm}$, while the values for PI film and 1 vol \% BTNPs/PI nanocomposite are $450 \mathrm{kV} / \mathrm{mm}$ and $300 \mathrm{kV} / \mathrm{mm}$, respectively. It is worth noting that when the volume percentage of the nanofiller increases from $3 \mathrm{vol} \%$ to $9 \mathrm{vol} \%$, the breakdown strength of both the BTNFs/PI and BTNPs/PI nanocomposites continuously decreases, which can be attributed to the inevitable aggregation of the nanofillers. As a result, the BTNFs/PI nanocomposite with $1 \mathrm{vol} \%$ BTNFs exhibits the highest energy density of $5.83 \mathrm{~J} / \mathrm{cm}^{3}$ under an electric field of $500 \mathrm{kV} / \mathrm{mm}$, slightly better than that of the pure PI film (Figure 9d). Therefore, although 1D nanofillers can enhance the breakdown strength of polymer-based composites, the dispersion of these 1D nanofillers at high concentrations must be enhanced in order to significantly improve the energy density of the composites. 


\subsection{The 2D Nanoplate/Linear Polymer Nanocomposites}

As previously discussed, the structural continuity and thermal conductivity of nanofillers are of great importance to the energy storage performance of polymer-based nanocomposites. Therefore, emerging 2D nanomaterials may provide new possibilities for the fabrication of high-performance dielectric capacitors [79-82]. Compared with 1D nanomaterials, 2D fillers with high aspect ratios can establish effective conductive barriers in nanocomposites to hinder the growth of electrical trees during the breakdown process and increasing breakdown strength [23]. In addition, the high thermal conductivity of 2D materials can effectively dissipate Joule heat, which is beneficial for enhancing the high-temperature performance of dielectrics.

Li et al. prepared a 2D polymer nanocomposite by dispersing boron nitride nanosheets (BNNSs) in the high $T_{\mathrm{g}}$ divinyltetramethyldisiloxane-bis(benzocyclobutene) (BCB) matrix, followed by thermal crosslinking. As a result, crosslinked-BCB (c-BCB)/BNNSs dielectric nanocomposites with stable cross-linking networks and BNNSs insulation networks were obtained (Figure 10a) [40]. Figure 10b,c summarizes the breakdown strength of the (c-BCB)/BNNSs nanocomposites. A high breakdown strength of $447 \mathrm{MV} / \mathrm{m}$ is achieved when incorporating $10 \mathrm{vol} \%$ BNNSs into the $c$-BCB matrix. The improvement in the breakdown strength of the (c-BCB)/BNNSs nanocomposites is attributed to the improvement of Young's modulus and the effective suppression of high-field electrical conduction by the introduction of BNNSs. In addition, the ultrahigh thermal conductivity of BNNSs ( $\sim 300$ to $2000 \mathrm{~W} /(\mathrm{m} / \mathrm{K}))$ is conducive to improving the breakdown strength at high temperatures. Specifically, the breakdown strength of $10 \mathrm{vol} \%$ (c-BCB)/BNNSs at $250{ }^{\circ} \mathrm{C}$ is $403 \mathrm{MV} / \mathrm{m}$, only $9.8 \%$ lower than that at $20^{\circ} \mathrm{C}$ (Figure 10d). In contrast, the breakdown strength of the pristine $c$-BCB film at $250{ }^{\circ} \mathrm{C}$ sharply decreases to $\sim 260 \mathrm{MV} / \mathrm{m}$ (Figure 10e).
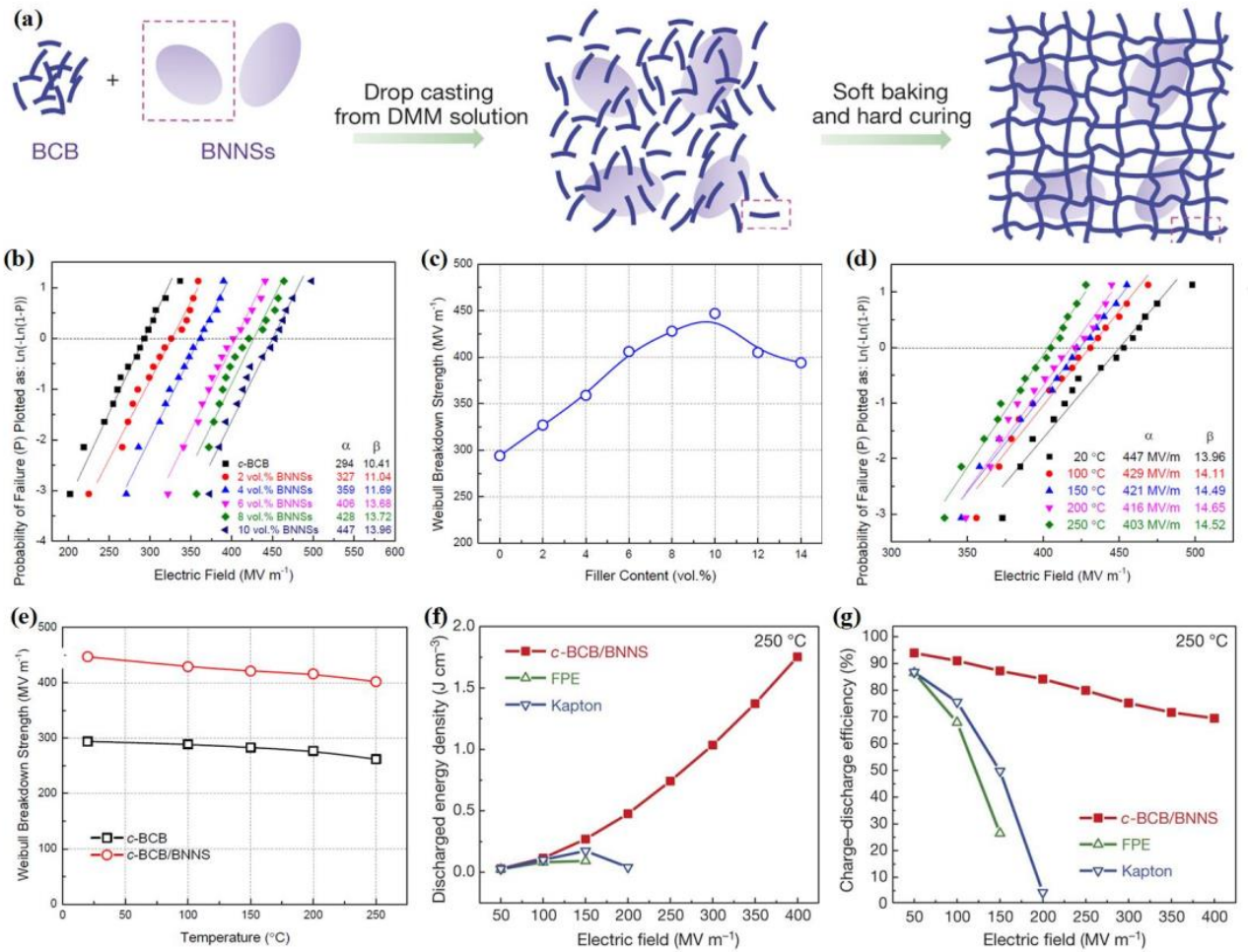

Figure 10. (a) Schematic of the preparation of $c-B C B / B N N S$ films. (b,c) Weibull breakdown strength of $c-B C B / B N N S$ as a function of the BNNSs content. (d) Weibull plots of $c$-BCB/BNNS with 10 vol \% of BNNSs at different temperatures. (e) Weibull breakdown strength of $c-B C B$ and $c-B C B / B N N S$ as a function of temperature. The dielectric breakdown strength was measured using the electrostatic pull-down method under a direct-current voltage ramp of $500 \mathrm{~V} \mathrm{~s}^{-1}$. (f, $\mathbf{g}$ ) Discharged energy density and efficiency of $c$-BCB/BNNS with $10 \mathrm{vol} \%$ of BNNSs at $250{ }^{\circ} \mathrm{C}$ (Measured at a frequency of $10 \mathrm{~Hz}$ ). Reproduced with permission from Ref. [40]. Copyright 2015, Springer Nature. 
Figure 10f,g shows the energy density and efficiency of composite films with $10 \mathrm{vol} \%$ BNNSs and two other high-temperature-resistant dielectrics at $250{ }^{\circ} \mathrm{C}$. Remarkably, the energy density of the $10 \mathrm{vol} \%(c-\mathrm{BCB}) / \mathrm{BNNS}$ composite film is $1.8 \mathrm{~J} / \mathrm{cm}^{3}$ at a relatively high electric field of $400 \mathrm{MV} / \mathrm{m}$, while fluorene polyester (FPE) and Kapton can only operate under low electric fields of $150 \mathrm{MV} / \mathrm{m}$ and $200 \mathrm{MV} / \mathrm{m}$ with ultralow discharge energy density. In addition, the efficiencies of FPE and Kapton sharply decrease from $~ 80 \%$ to less than $30 \%$ when the electric field increases to $150 \mathrm{MV} / \mathrm{m}$, while the efficiency of (c-BCB)/BNNSs is still higher than $70 \%$ at $400 \mathrm{MV} / \mathrm{m}$.

According to Li et al., the energy-storage performance of polymer nanocomposites is effectively improved by incorporating BNNSs into polymer matrices, especially for hightemperature operation. However, the typical BNNSs preparation method, liquid-phase exfoliation, is both time-consuming and low-yield, which greatly hinders the scale-up of BNNSs production [83]. In addition to $\mathrm{BNNSs}, \gamma-\mathrm{Al}_{2} \mathrm{O}_{3}$ is another typical wide bandgap material, and its dielectric constant (9-10) is higher than that of BNNSs (3-4). Moreover, $\gamma-\mathrm{Al}_{2} \mathrm{O}_{3}$ usually exhibits a high breakdown strength of $600-800 \mathrm{MV} / \mathrm{m}$. Therefore, $\gamma-\mathrm{Al}_{2} \mathrm{O}_{3}$ is an ideal nanofiller for the fabrication of high-performance polymer nanocomposites.

Based on this, $\mathrm{Li}$ et al. prepared various $c$-BCB-based composites by introducing $\mathrm{Al}_{2} \mathrm{O}_{3}$ nanoparticles, $\mathrm{Al}_{2} \mathrm{O}_{3}$ nanowires, and $\mathrm{Al}_{2} \mathrm{O}_{3}$ nanoplates as fillers, denoted $c-\mathrm{BCB} / \mathrm{Al}_{2} \mathrm{O}_{3}-\mathrm{NPs}, c$ $\mathrm{BCB} / \mathrm{Al}_{2} \mathrm{O}_{3}-\mathrm{NWs}$, and $c-\mathrm{BCB} / \mathrm{Al}_{2} \mathrm{O}_{3}-\mathrm{NPLs}$, respectively (Figure 11) [84]. Figure 12a presents the dielectric constants of the $\mathrm{Al}_{2} \mathrm{O}_{3}$-based polymer composites and the $c$ - $\mathrm{BCB} / \mathrm{BNNSs}$ composite reported in [40]. All the reported $\mathrm{Al}_{2} \mathrm{O}_{3}$-based polymer composites exhibit higher dielectric constants than the $c$-BCB/BNNSs composite at the same filler content, due to the relatively high permittivity of $\mathrm{Al}_{2} \mathrm{O}_{3}$. Moreover, compared with $c-\mathrm{BCB} / \mathrm{Al}_{2} \mathrm{O}_{3}-\mathrm{NPs}_{\text {, the }}$ dielectric constants of $c-\mathrm{BCB} / \mathrm{Al}_{2} \mathrm{O}_{3}-\mathrm{NWs}$ and $c-\mathrm{BCB} / \mathrm{Al}_{2} \mathrm{O}_{3}-\mathrm{NPLs}$ with the same nanofiller content are much higher, which can be attributed to the larger dipole moments caused by the higher aspect ratios of $\mathrm{Al}_{2} \mathrm{O}_{3}-\mathrm{NWs}$ and $\mathrm{Al}_{2} \mathrm{O}_{3}-\mathrm{NPLs}$.



Figure 11. Schematic of the preparation of $c-B C B / \mathrm{Al}_{2} \mathrm{O}_{3}-\mathrm{NPs}$, -NWs and -NPLs nanocomposites. Reproduced with permission from Ref. [84]. Copyright 2019, Wiley-VCH. 
(a)

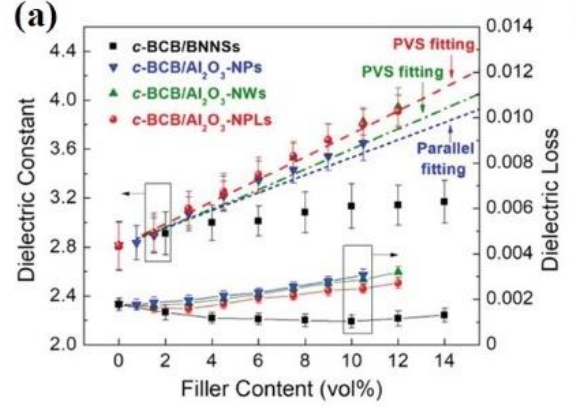

(d)

NPs

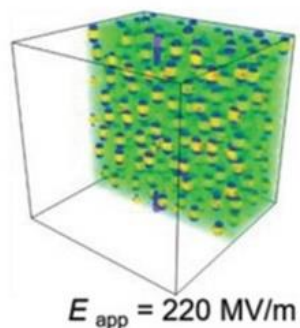

NWs

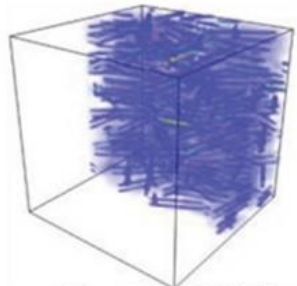

$E_{\text {app }}=200 \mathrm{MV} / \mathrm{m}$

NPLs

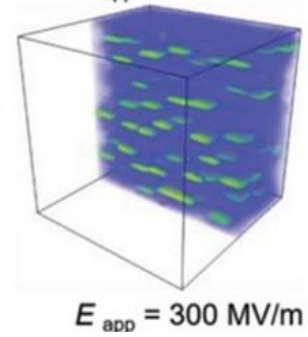

(b)

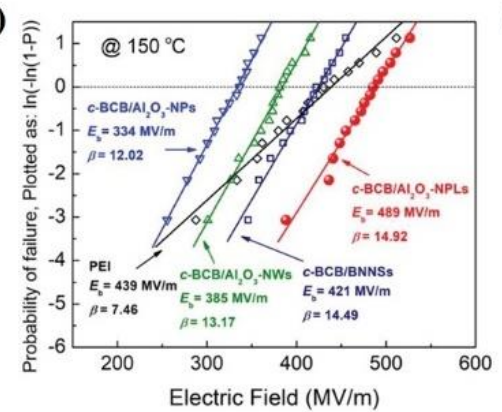

(c)
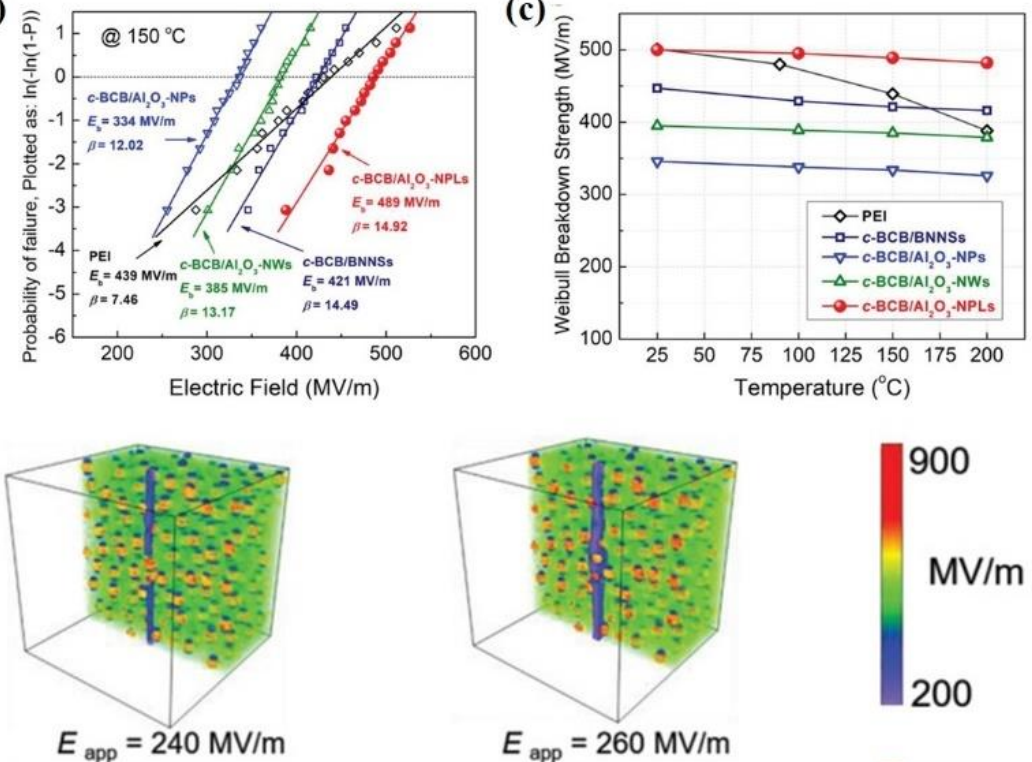

900

$\mathrm{MV} / \mathrm{m}$

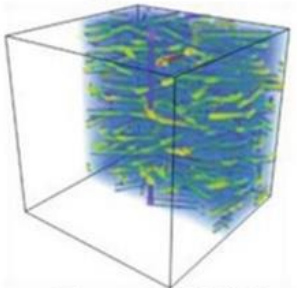

$E_{\text {app }}=260 \mathrm{MV} / \mathrm{m}$

200

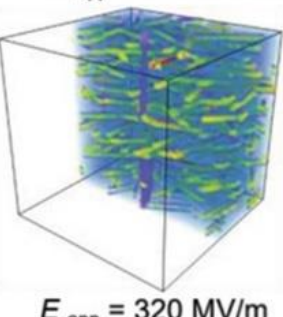

800

$\mathrm{MV} / \mathrm{m}$

200

$E_{\text {app }}=300 \mathrm{MV} / \mathrm{m}$


$\mathrm{MV} / \mathrm{m}$

Figure 12. (a) Dielectric constant and loss of the composites as a function of filler content measured at room temperature and $1 \mathrm{kHz}$. (b) Weibull statistic of dielectric breakdown strength of PEI and the nanocomposites at $150{ }^{\circ} \mathrm{C}$. (c) Temperaturedependent Weibull breakdown strength of PEI and the nanocomposites at $150{ }^{\circ} \mathrm{C}$. (d) The corresponding electric field distribution was computed by phase-field simulations of the $c$-BCB nanocomposites with 7.5 vol $\% \mathrm{Al}_{2} \mathrm{O}_{3} \mathrm{NPs}_{\mathrm{s}} \mathrm{NWs}$, and NPLs at $150{ }^{\circ} \mathrm{C}$ and varied applied electric fields. Reproduced with permission from Ref. [84]. Copyright 2019, Wiley-VCH.

The breakdown strength of various dielectric nanocomposites at $150{ }^{\circ} \mathrm{C}$ is shown in Figure $12 \mathrm{~b}$. On one hand, nanocomposites containing $2 \mathrm{D}$ nanofillers $\left(c-\mathrm{BCB} / \mathrm{Al}_{2} \mathrm{O}_{3}-\mathrm{NPLs}\right.$ and $c-\mathrm{BCB} / \mathrm{BNNSs}$ ) exhibit higher breakdown strengths than nanocomposites containing $0 \mathrm{D} \mathrm{Al} \mathrm{O}_{3}$ nanoparticles $\left(c-\mathrm{BCB} / \mathrm{Al}_{2} \mathrm{O}_{3} \mathrm{NPs}\right)$ and $1 \mathrm{D} \mathrm{Al} \mathrm{O}_{3}$ nanowires $\left(c-\mathrm{BCB} / \mathrm{Al}_{2} \mathrm{O}_{3} \mathrm{NWs}\right.$ ). On the other hand, compared with the nanocomposite containing $10 \mathrm{vol} \% \mathrm{BNNSs}$, the $7.5 \mathrm{vol} \% \mathrm{Al}_{2} \mathrm{O}_{3}$-NPLs nanocomposite has a higher breakdown strength $(489 \mathrm{MV} / \mathrm{m}$ vs. $421 \mathrm{MV} / \mathrm{m}$ ). Moreover, the breakdown strength temperature stability of all the $\mathrm{Al}_{2} \mathrm{O}_{3^{-}}$ based polymer composites is higher than that of pure PEI film (Figure 12c). Specifically, the breakdown strength of $c-\mathrm{BCB} / \mathrm{Al}_{2} \mathrm{O}_{3}$ NPLs is almost constant over a wide temperature range of $25^{\circ} \mathrm{C}$ to $200{ }^{\circ} \mathrm{C}$, while a significant decrease of $20 \%$ can be observed for PEI film (from 501 to $400 \mathrm{MV} / \mathrm{m}$ ).

To further understand the breakdown strength enhancement of $\mathrm{Al}_{2} \mathrm{O}_{3}$-based polymer composites, phase-field simulations of various composites were characterized, as shown in Figure 12d. For the $c-\mathrm{BCB} / \mathrm{Al}_{2} \mathrm{O}_{3} \mathrm{NPs}$ and the $c-\mathrm{BCB} / \mathrm{Al}_{2} \mathrm{O}_{3} \mathrm{NWs}$ composites, the electric fields are highly concentrated around the NPs and at the vertices of the NWs, 
respectively, which leads to the easy formation of breakdown paths. In contrast, the NPLs effectively disperse the applied electric field through the polymer matrix to mitigate the inhomogeneous distribution of local electric fields, resulting in higher breakdown strength.

Due to its high dielectric constant and the excellent temperature stability of its breakdown strength, $c-\mathrm{BCB} / \mathrm{Al}_{2} \mathrm{O}_{3}$ NPLs exhibit better high-temperature energy storage properties than current high-temperature dielectrics. As shown in Figure 13a, the energy density of $c-\mathrm{BCB} / \mathrm{Al}_{2} \mathrm{O}_{3}-7.5 \mathrm{vol} \% \mathrm{NPLs}$ at $150{ }^{\circ} \mathrm{C}$ is $4.3 \mathrm{~J} / \mathrm{cm}^{3}$, while typical values for other high-temperature dielectrics are below $2.5 \mathrm{~J} / \mathrm{cm}^{3}$. Moreover, the efficiency of $c-\mathrm{BCB} / \mathrm{Al}_{2} \mathrm{O}_{3}$ NPLs remains $>90 \%$ under a high electric field of $450 \mathrm{MV} / \mathrm{m}$ (Figure $13 \mathrm{~b}$ ). Even at $200{ }^{\circ} \mathrm{C}$, the energy storage performance of $c-\mathrm{BCB} / \mathrm{Al}_{2} \mathrm{O}_{3} \mathrm{NPLs}$ is still much better than that of other dielectrics. For instance, the energy density of $c-\mathrm{BCB} / \mathrm{Al}_{2} \mathrm{O}_{3} \mathrm{NPLs}$ is about $3.02 \mathrm{~J} / \mathrm{cm}^{3}$ and the efficiency is $>75 \%$ at $450 \mathrm{MV} / \mathrm{m}$ (Figure 13c,d).

(a)
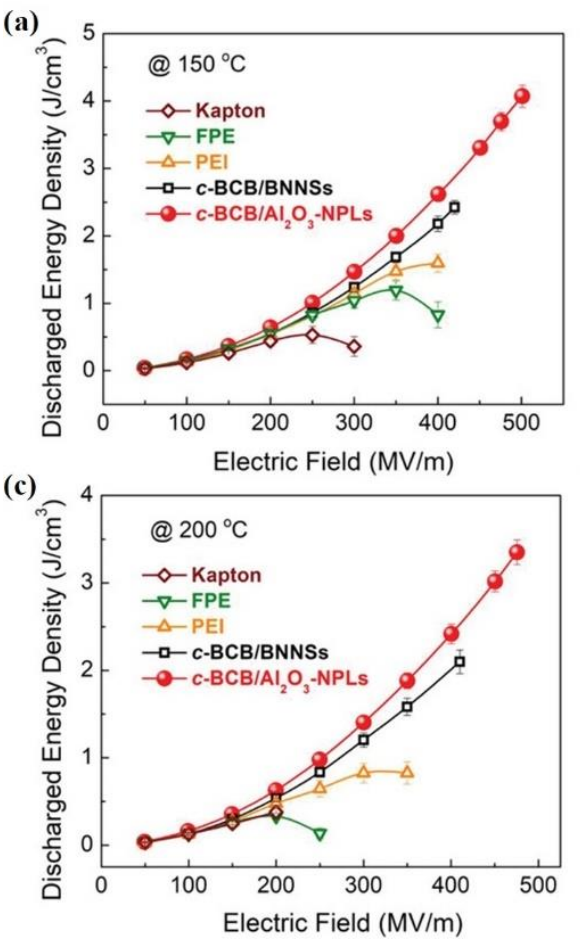

(b)

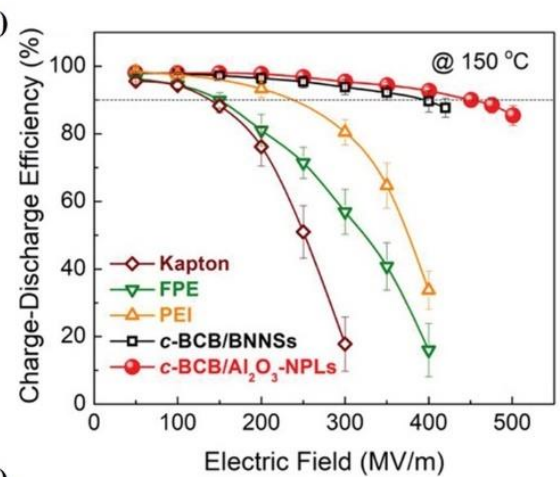

(d)

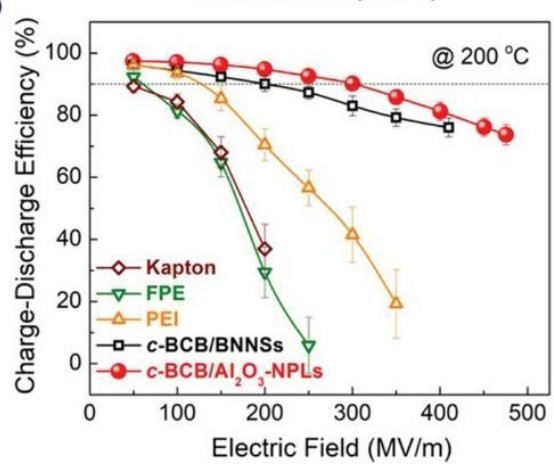

Figure 13. Discharged energy density and charge-discharge efficiency of high-temperature dielectric polymers and the $c-\mathrm{BCB}$ nanocomposites measured at $150{ }^{\circ} \mathrm{C}(\mathbf{a}, \mathbf{b})$ and $200{ }^{\circ} \mathrm{C}(\mathbf{c}, \mathbf{d})$. Reproduced with permission from Ref. [84]. Copyright 2019, Wiley-VCH.

\section{Conclusions and Future Perspective}

In summary, compared with ferroelectrics, relaxor ferroelectrics, and anti-ferroelectrics, linear dielectric polymers exhibit obvious advantages in charge-discharge efficiency but usually suffer from low energy density. Therefore, the energy density of linear polymer dielectrics must be significantly improved to realize their practical application in electrical power systems. To date, various methods have been developed to effectively improve the energy storage performance of linear dielectrics. This improvement is mainly achieved in one of two ways: increasing the breakdown strength and enhancing the dielectric constant. In terms of increasing the breakdown strength of linear polymers, preparing polymer blends has proven to be effective for reducing the weak points in polymers. In addition, incorporating high-permittivity nanofillers with linear polymer matrices and controlling polymer/filler interfaces can improve the permittivity of polymer composites while ensuring that the breakdown strength does not significantly decrease. In this way, energy density is enhanced.

Various linear polymer nanocomposites with improved energy storage performance have been obtained. By compounding wide bandgap $\mathrm{Al}_{2} \mathrm{O}_{3}$ nanoparticles with a PEEU 
matrix, a discharge energy density of up to $27 \mathrm{~J} / \mathrm{cm}^{3}$ can be obtained at room temperature with the resulting $\mathrm{Al}_{2} \mathrm{O}_{3} / \mathrm{PEEU}$ composite, which has a charge-discharge efficiency of $>90 \%$ [43]. The high-temperature energy storage performance of linear dielectrics has also been significantly improved. The incorporation of $2 \mathrm{D} \mathrm{Al}_{2} \mathrm{O}_{3}$ nanoplates with a $\mathrm{BCB}$ matrix results in a nanocomposite with an energy density of $3 \mathrm{~J} / \mathrm{cm}^{3}$ at $200{ }^{\circ} \mathrm{C}$. More importantly, the efficiency of this nanocomposite is $>75 \%$ at this temperature [84]. However, despite the substantial amount of progress made in improving the properties of linear polymer dielectrics, these dielectrics still fall short of the requirements for their desired applications, and the future development of linear dielectrics should include the following aspects:

1. More attention should be paid to the chemical or physical modification of the molecular structures and nanostructures of linear dielectric polymers to improve their saturation polarization levels and breakdown strength. This is the most fundamental and effective way to improve the energy density of linear dielectric polymers without sacrificing their efficiency.

2. The polarization level of linear dielectric polymers can be effectively improved by the introduction of high-permittivity nanofillers but their breakdown strength will be correspondingly reduced, due to the inevitable structural defects caused by the nanofiller phase. Therefore, innovative approaches should be developed to improve the dispersion uniformity of nanofillers and to optimize polymer/filler interface compatibility.

3. The conduction loss of polymer nanocomposites usually sharply increases with increasing electric field and temperature, which results in a significant decrease in chargedischarge efficiency. To suppress this temperature- and field-dependent conduction loss, surface functionalization and molecular engineering should be considered to further optimize polymer dielectric materials.

4. Finally, the development of feasible, low-cost, and scaled-up manufacturing processes is critical for the industrial application of dielectric materials. This endeavor mainly includes two aspects: the simplification of the existing dielectric material preparation approaches and the development of large-scale production apparatus.

Author Contributions: Conceptualization, Y.-H.L. and L.D.; data curation, L.D.; writing-original draft preparation, L.D.; writing-review and editing, Y.-H.L. and C.-W.N.; supervision, Y.-H.L.; funding acquisition, C.-W.N. and L.D. All authors have read and agreed to the published version of the manuscript.

Funding: This work was funded by the National Natural Science Foundation of China (No.51788104 and 5210020257), China Postdoctoral Science Foundation (No. 2021TQ0163), the Open Youth Fund project of Foshan (South China) Institute of New Materials (No. 2021AYF25011) and the Shuimu Tsinghua Scholar Program (No. 2020SM101).

Conflicts of Interest: The authors declare no conflict of interest.

\section{References}

1. Hao, X.H. A review on the dielectric materials for high energy-storage application. J. Adv. Dielectr. 2013, 3, 1330001. [CrossRef]

2. Palneedi, H.; Peddigari, M.; Hwang, G.T.; Jeong, D.Y.; Ryu, J. High-performance dielectric ceramic films for energy storage capacitors: Progress and outlook. Adv. Funct. Mater. 2018, 28, 1803665. [CrossRef]

3. Pan, H.; Li, F.; Liu, Y.; Zhang, Q.H.; Wang, M.; Lan, S.; Zheng, Y.P.; Ma, J.; Gu, L.; Shen, Y.; et al. Ultrahigh-energy density lead-free dielectric films via polymorphic nanodomain design. Science 2019, 365, 578-582. [CrossRef] [PubMed]

4. Simon, P.; Gogotsi, Y. Perspectives for electrochemical capacitors and related devices. Nat. Mater. 2020, 19, 1151-1163. [CrossRef] [PubMed]

5. Wang, Y.G.; Song, Y.F.; Xia, Y.Y. Electrochemical capacitors: Mechanism, materials, systems, characterization and applications. Chem. Soc. Rev. 2016, 45, 5925-5950. [CrossRef]

6. Goodenough, J.B.; Park, K.S. The Li-Ion rechargeable battery: A perspective. J. Am. Chem. Soc. 2013, 135, 1167-1176. [CrossRef]

7. Nitta, N.; Wu, F.X.; Lee, J.T.; Yushin, G. Li-ion battery materials: Present and future. Mater. Today 2015, 18, 252-264. [CrossRef]

8. Mekhilef, S.; Saidur, R.; Safari, A. Comparative study of different fuel cell technologies. Renew. Sustain. Energy Rev. 2012, 16, 981-989. [CrossRef] 
9. Sharaf, O.Z.; Orhan, M.F. An overview of fuel cell technology: Fundamentals and applications. Renew. Sustain. Energy Rev. 2014, 32, 810-853. [CrossRef]

10. Pan, H.; Ma, J.; Ma, J.; Zhang, Q.H.; Liu, X.Z.; Guan, B.; Gu, L.; Zhang, X.; Zhang, Y.J.; Li, L.L.; et al. Giant energy density and high efficiency achieved in bismuth ferrite-based film capacitors via domain engineering. Nat. Commun. 2018, 9, 1813. [CrossRef]

11. Ali, F.Z.; Liu, X.H.; Zhou, D.Y.; Yang, X.R.; Xu, J.; Schenk, T.; Müller, J.; Schroeder, U.; Cao, F.; Dong, X.L. Silicon-doped hafnium oxide anti-ferroelectric thin films for energy storage. J. Appl. Phys. 2017, 122, 144105. [CrossRef]

12. Ramesh, S.; Shutzberg, B.A.; Huang, C.; Jie, G.; Giannelis, E.P. Dielectric nanocomposites for integral thin film capacitors: Materials design, fabrication and integration issues. IEEE Trans. Adv. Packag. 2003, 26, 17-24. [CrossRef]

13. Li, Q.; Han, K.; Gadinski, M.R.; Zhang, G.; Wang, Q. High energy and power density capacitors from solution-processed ternary ferroelectric polymer nanocomposites. Adv. Mater. 2014, 26, 6244-6249. [CrossRef]

14. Li, J.L.; Shen, Z.H.; Chen, X.H.; Yang, S.; Zhou, W.L.; Wang, M.W.; Wang, L.H.; Kou, Q.W.; Liu, Y.C.; Li, Q.; et al. Grainorientation-engineered multilayer ceramic capacitors for energy storage applications. Nat. Mater. 2020, 19, 999-1005. [CrossRef] [PubMed]

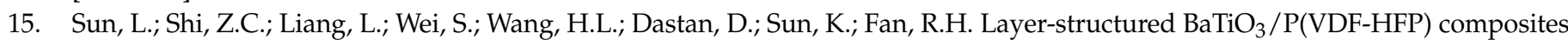
with concurrently improved dielectric permittivity and breakdown strength toward capacitive energy-storage applications. $J$. Mater. Chem. C 2020, 8, 10257-10265. [CrossRef]

16. Kotz, R.; Carlen, M. Principles and applications of electrochemical capacitors. Electrochim. Acta 2000, 45, 2483-2498. [CrossRef]

17. Chen, Q.; Shen, Y.; Zhang, S.H.; Zhang, Q.M. Polymer-based dielectrics with high energy storage density. Annu. Rev. Mater. Res. 2015, 45, 433-458. [CrossRef]

18. Yao, Z.; Song, Z.; Hao, H.; Yu, Z.; Cao, M.; Zhang, S.; Lanagan, M.T.; Liu, H. Homogeneous/inhomogeneous-structured dielectrics and their energy-storage performances. Adv. Mater. 2017, 29, 1601727. [CrossRef]

19. Fredin, L.A.; Li, Z.; Ratner, M.A.; Lanagan, M.T.; Marks, T.J. Enhanced energy storage and suppressed dielectric loss in oxide core-shell-polyolefin nanocomposites by moderating internal surface area and increasing shell thickness. Adv. Mater. 2012, 24, 5946-5953. [CrossRef]

20. Fletcher, N.H.; Hilton, A.D.; Ricketts, B.W. Optimization of energy storage density in ceramic capacitors. J. Phys. D Appl. Phys. 1996, 29, 253-258. [CrossRef]

21. Huang, X.Y.; Sun, B.; Zhu, Y.K.; Li, S.T.; Jiang, P.K. High-k polymer nanocomposites with 1D filler for dielectric and energy storage applications. Prog. Mater. Sci. 2019, 100, 187-225. [CrossRef]

22. Kwon, S.; Hackenberger, W.; Alberta, E.; Furman, E.; Lanagan, M. Nonlinear dielectric ceramics and their applications to capacitors and tunable dielectrics. IEEE Electr. Insul. Mag. 2011, 27, 43-55. [CrossRef]

23. Jiang, Y.D.; Zhou, M.J.; Shen, Z.H.; Zhang, X.; Pan, H.; Lin, Y.H. Ferroelectric polymers and their nanocomposites for dielectric energy storage applications. APL Mater. 2021, 9, 020905. [CrossRef]

24. Zhang, H.B.; Marwat, M.A.; Xie, B.; Ashtar, M.; Liu, K.; Zhu, Y.W.; Zhang, L.; Fan, P.Y.; Samart, C.; Ye, Z.G. Polymer matrix nanocomposites with 1D Ceramic nanofillers for energy storage capacitor applications. ACS Appl. Mater. Interfaces 2020, $12,1-37$. [CrossRef]

25. Li, F.; Zhang, S.J.; Yang, T.N.; Xu, Z.; Zhang, N.; Liu, G.; Wang, J.J.; Wang, J.; Cheng, Z.X.; Ye, Z.G.; et al. The origin of ultrahigh piezoelectricity in relaxor-ferroelectric solid solution crystals. Nat. Commun. 2016, 7, 13807. [CrossRef] [PubMed]

26. Zhao, L.; Liu, Q.; Gao, J.; Zhang, S.J.; Li, J.F. Lead-free antiferroelectric silver niobate tantalate with high energy storage performance. Adv. Mater. 2017, 29, 1071824. [CrossRef] [PubMed]

27. Li, J.L.; Li, F.; Xu, Z.; Zhang, S.J. Multilayer lead-free ceramic capacitors with ultrahigh energy density and efficiency. Adv. Mater. 2018, 30, 1802155. [CrossRef]

28. Han, C.C.; Zhang, X.H.; Chen, D.; Ma, Y.H.; Zhao, C.W.; Yang, W.T. Enhanced dielectric properties of sandwich-Structured biaxially oriented polypropylene by grafting hyper-Branched aromatic polyamide as surface layers. J. Appl. Polym. Sci. 2020, 137, 48990. [CrossRef]

29. Choudhury, A. Dielectric and piezoelectric properties of polyetherimide/ $\mathrm{BaTiO}_{3}$ nanocomposites. Mater. Chem. Phys. 2010, 121, 280-285. [CrossRef]

30. Wu, S.Y.; Huang, Y.L.; Ma, C.-C.M.; Yuen, S.M.; Teng, C.C.; Yang, S.Y. Mechanical, thermal and electrical properties of aluminum nitride/polyetherimide composites. Compos. Part A 2011, 42, 1573-1583. [CrossRef]

31. Hao, J.G.; Li, W.; Zhai, J.W.; Chen, H. Progress in high-strain perovskite piezoelectric ceramics. Mater. Sci. Eng. R Rep. 2019, 135, 1-57. [CrossRef]

32. Wang, Q.; Zhu, L. Polymer nanocomposites for electrical energy storage. J. Polym. Sci. Part B Polym. Phys. 2011, 49, 1421-1429. [CrossRef]

33. Chu, B.J.; Zhou, X.; Ren, K.L.; Neese, B.; Lin, M.R.; Wang, Q.; Bauer, F.; Zhang, Q.M. A dielectric polymer with high electric energy density and fast discharge speed. Science 2006, 313, 334-336. [CrossRef]

34. Dang, Z.M.; Yuan, J.K.; Zha, J.W.; Zhou, T.; Li, S.T.; Hu, G.H. Fundamentals, processes and applications of high-permittivity polymer matrix composites. Prog. Mater. Sci. 2012, 57, 660-723. [CrossRef]

35. Tan, D.Q. Review of polymer-based nanodielectric exploration and film scale-up for advanced capacitors. Adv. Funct. Mater. 2020, 30, 1808567. [CrossRef] 
36. Xiong, J.; Wang, X.; Zhang, X.; Xie, Y.C.; Lu, J.Y.; Zhang, Z.C. How the biaxially stretching mode influence dielectric and energy storage properties of polypropylene films. J. Appl. Polym. Sci. 2020, 138, 50029. [CrossRef]

37. Rabuffi, M.; Picci, G. Status quo and future prospects for metallized polypropylene energy storage capacitors. IEEE Trans. Plasma Sci. 2002, 30, 1939-1942. [CrossRef]

38. Li, Q.; Yao, F.Z.; Liu, Y.; Zhang, G.Z.; Wang, H.; Wang, Q. High-temperature dielectric materials for electrical energy storage. Annu. Rev. Mater. Res. 2018, 48, 219-243. [CrossRef]

39. Vanherck, K.; Koeckelberghs, G.; Vankelecom, I.F.J. Crosslinking polyimides for membrane applications: A review. Prog. Polym. Sci. 2013, 38, 874-896. [CrossRef]

40. Li, Q.; Chen, L.; Gadinski, M.R.; Zhang, S.; Zhang, G.; Li, U.; Iagodkine, E.; Haque, A.; Chen, L.Q.; Jackson, N.; et al. Flexible high-temperature dielectric materials from polymer nanocomposites. Nature 2015, 523, 576-579. [CrossRef]

41. Azizi, A.; Gadinski, M.R.; Li, Q.; Al Saud, M.A.; Wang, J.; Wang, Y.; Wang, B.; Liu, F.; Chen, L.Q.; Alem, N.; et al. High-performance polymers sandwiched with chemical vapor deposited hexagonal boron nitrides as scalable high-temperature dielectric materials. Adv. Mater. 2017, 29, 1701864. [CrossRef] [PubMed]

42. Zhao, X.C.; Bi, Y.J.; Xie, J.H.; Hu, J.; Sun, S.L.; Song, S.X. Enhanced dielectric, energy storage and tensile properties of BaTiO ${ }_{3}-$ $\mathrm{NH}_{2}$ /low-density polyethylene nanocomposites with POE-GMA as interfacial modifier. Polym. Test. 2021, 95, 107094. [CrossRef]

43. Zhang, T.; Chen, X.; Thakur, Y.; Lu, B.; Zhang, Q.Y.; Runt, J.; Zhang, Q.M. A highly scalable dielectric metamaterial with superior capacitor performance over a broad temperature. Sci. Adv. 2020, 6, eaax6622. [CrossRef]

44. Mittal, A.; Jain, V.; Mittal, J. Temperature dependence of dielectric constant on pure polymethyl methacrylate. Asian J. Chem. 2001, $13,1216-1218$.

45. Liu, G.; Zhang, T.D.; Feng, Y.; Zhang, Y.Q.; Zhang, C.H.; Zhang, Y.; Wang, X.B.; Chi, Q.G.; Chen, Q.G.; Lei, Q.Q. Sandwichstructured polymers with electrospun boron nitrides layers as high-temperature energy storage dielectrics. Chem. Eng. J. 2020, 389, 124443. [CrossRef]

46. Marwat, M.A.; Xie, B.; Zhu, Y.W.; Fan, P.Y.; Ma, W.G.; Liu, H.M.; Ashtar, M.; Xiao, J.Z.; Salamon, D.; Samart, C.; et al. Largely enhanced discharge energy density in linear polymer nanocomposites by designing a sandwich structure. Compos. Part A 2019, 121, 115-122. [CrossRef]

47. Chen, C.; Xing, J.W.; Cui, Y.; Zhang, C.H.; Feng, Y.; Zhang, Y.Q.; Zhang, T.D.; Chi, Q.G.; Wang, X.; Lei, Q.Q. Designing of ferroelectric/linear dielectric bilayer films: An effective way to improve the energy storage performances of polymer-based capacitors. J. Phys. Chem. C 2020, 124, 5920-5927. [CrossRef]

48. Li, W.P.; Jiang, L.; Zhang, X.; Shen, Y.; Nan, C.W. High-energy-density dielectric films based on polyvinylidene fluoride and aromatic polythiourea for capacitors. J. Mater. Chem. A 2014, 2, 15803-15807. [CrossRef]

49. Wang, J.; Xie, Y.C.; Liu, J.J.; Zhang, Z.C.; Zhuang, Q.; Kong, J. Improved energy storage performance of linear dielectric Polymer nanodielectrics with polydopamine coated BN Nanosheets. Polymers 2018, 10, 1349. [CrossRef]

50. Artbauer, J. Electric strength of polymers. J. Phys. Chem. D 1996, 29, 446-456. [CrossRef]

51. White, R.P.; Lipson, J.E.G. Polymer free volume and its connection to the glass transition. Macromolecules 2016, 49, 3987-4007. [CrossRef]

52. Yong, W.F.; Chung, T.S. Mechanically strong and flexible hydrolyzed polymers of intrinsic microporosity (PIM-1) membranes. J. Polym. Sci. Part B Polym. Phys. 2017, 55, 344-354. [CrossRef]

53. Zhang, Q.Y.; Chen, X.; Zhang, B.; Zhang, T.; Lu, W.C.; Chen, Z.; Liu, Z.Y.; Kim, S.H.; Donovan, B.; Warzoha, R.J.; et al. Hightemperature polymers with record-high breakdown strength enabled by rationally designed chain-packing behavior in blends. Matter 2021, 4, 1-12. [CrossRef]

54. Halasa, A.F.; Wathen, G.D.; Hsu, W.L.; Matrana, B.A.; Massie, J.M. Relationship between interchain spacing of amorphous polymers and blend miscibility as determined by wide-angle X-ray-scattering. J. Appl. Polym. Sci. 1991, 43, 183-190. [CrossRef]

55. Xu, J.; Wang, S.H.; Wang, G.-J.N.; Zhu, C.X.; Luo, S.C.; Jin, L.H.; Gu, X.D.; Chen, S.C.; Feig, V.R.; To, J.W.F.; et al. Highly stretchable polymer semiconductor films through the nanoconfinement effect. Science 2017, 355, 59. [CrossRef]

56. Xu, Y.F.; Wang, X.X.; Zhou, J.W.; Song, B.; Jiang, Z.; Lee, E.M.Y.; Huberman, S.; Gleason, K.K.; Chen, G. Molecular engineered conjugated polymer with high thermal conductivity. Sci. Adv. 2018, 4, eaar3031. [CrossRef]

57. Shanker, A.; Li, C.; Kim, G.H.; Gidley, D.; Pipe, K.P.; Kim, J. High thermal conductivity in electrostatically engineered amorphous polymers. Sci. Adv. 2017, 3, e1700342. [CrossRef]

58. Cheng, Z.X.; Lin, M.R.; Wu, S.; Thakur, Y.; Zhou, Y.; Jeong, D.Y.; Shen, Q.D.; Zhang, Q.M. Aromatic poly(arylene ether urea) with high dipole moment for high thermal stability and high energy density capacitors. Appl. Phys. Lett. 2015, 106, 202902. [CrossRef]

59. Thakur, Y.; Dong, R.; Lin, M.R.; Wu, S.; Cheng, Z.X.; Hou, Y.; Bernholc, J.; Zhang, Q.M. Optimizing nanostructure to achieve high dielectric response with low loss in strongly dipolar polymers. Nano Energy 2015, 16, 227-234. [CrossRef]

60. Ahmad, A.; Tong, H.; Fan, T.; Xu, J. All—Organic polymer blend dielectrics of poly (arylene ether urea) and polyimide: Toward high energy density and high temperature applications. J. Polym. Sci. 2021, 59, 1414-1423. [CrossRef]

61. Zhang, X.; Shen, Y.; Zhang, Q.; Gu, L.; Hu, Y.; Du, J.; Lin, Y.; Nan, C.W. Ultrahigh energy density of polymer nanocomposites containing $\mathrm{BaTiO}_{3} @ \mathrm{TiO}_{2}$ nanofibers by atomic-scale interface engineering. Adv. Mater. 2015, 27, 819-824. [CrossRef]

62. Mao, X.; Guo, W.F.; Li, C.Z.; Yang, J.; Du, L.R.; Hu, W.C.; Tang, X.Z. Low-temperature synthesis of polyimide/poly(vinylidene fluoride) composites with excellent dielectric property. Mater. Lett. 2017, 193, 213-215. [CrossRef] 
63. Zhou, Y.J.; Liu, Q.X.; Chen, F.J.; Zhao, Y.T.; Yang, W.Y.; He, X.; Mao, X.L.; Yang, Y.J.; Xu, J.H. Enhanced breakdown strength and energy storage density in polyurea all-organic composite films. Mater. Res. Express 2019, 6, 115325. [CrossRef]

64. Mansour, D.-E.A.; Abdel-Gawad, N.M.K.; El Dein, A.Z.; Ahmed, H.M.; Darwish, M.M.F.; Lehtonen, M. Recent advances in polymer nanocomposites based on polyethylene and polyvinylchloride for power cables. Materials 2021, 14, 66. [CrossRef]

65. Prateek, S.; Thakur, V.K.; Gupta, R.K. Recent progress on ferroelectric polymer-based nanocomposites for high energy density capacitors: Synthesis, dielectric properties, and future aspects. Chem. Rev. 2016, 116, 4260-4317. [CrossRef]

66. Zhang, X.; Li, B.W.; Dong, L.J.; Liu, H.X.; Chen, W.; Shen, Y.; Nan, C.W. Superior energy storage performances of polymer nanocomposites via modification of filler/polymer interfaces. Adv. Mater. Interfaces 2018, 5, 1800096. [CrossRef]

67. Ai, D.; Li, H.; Zhou, Y.; Ren, L.K.; Han, Z.B.; Yao, B.; Zhou, W.; Zhao, L.; Xu, J.M.; Wang, Q. Tuning nanofillers in in situ prepared polyimide nanocomposites for high-temperature capacitive energy storage. Adv. Energy Mater. 2020, 10, 1903881. [CrossRef]

68. Jiang, B.; Iocozzia, J.; Zhao, L.; Zhang, H.F.; Harn, Y.W.; Chen, Y.H.; Lin, Z.Q. Barium titanate at the nanoscale: Controlled synthesis and dielectric and ferroelectric properties. Chem. Soc. Rev. 2019, 48, 1194-1228. [CrossRef]

69. Stamate, M.D. On the dielectric properties of dc magnetron $\mathrm{TiO}_{2}$ thin films. Appl. Surf. Sci. 2003, 218, 317-322. [CrossRef]

70. Qi, P.; Zhai, J.W.; Yao, X. Microwave dielectric properties of the $\left(\mathrm{Ba}_{\mathrm{x}} \mathrm{Sr}_{1-\mathrm{x}}\right) \mathrm{TiO}_{3}$ thin films on alumina substrate. Ceram. Int. 2012, 38, 197-200. [CrossRef]

71. Sun, W.D.; Lu, X.J.; Jiang, J.Y.; Zhang, X.; Hu, P.H.; Li, M.; Lin, Y.H.; Nan, C.W.; Shen, Y. Dielectric and energy storage performances of polyimide $/ \mathrm{BaTiO}_{3}$ nanocomposites at elevated temperatures. J. Appl. Phys. 2017, 121, 244101. [CrossRef]

72. Niu, Y.J.; Wang, H. Dielectric nanomaterials for power energy storage: Surface modification and characterization. ACS Appl. Nano Mater. 2019, 2, 627-642. [CrossRef]

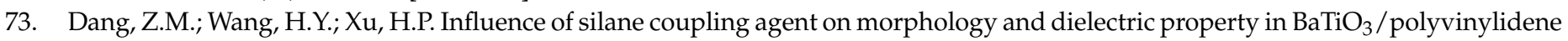
fluoride composites. Appl. Phys. Lett. 2006, 89, 112902. [CrossRef]

74. Zhou, T.; Zha, J.W.; Cui, R.Y.; Fan, B.H.; Yuan, J.K.; Dang, Z.M. Improving dielectric properties of $\mathrm{BaTiO}_{3} /$ ferroelectric polymer composites by employing surface hydroxylated $\mathrm{BaTiO}_{3}$ nanoparticles. ACS Appl. Mater. Interfaces 2011, 3, 2184-2188. [CrossRef]

75. Yu, K.; Niu, Y.J.; Zhou, Y.C.; Bai, Y.Y.; Wang, H.; Randall, C. Nanocomposites of surface-modified BaTiO 3 nanoparticles filled ferroelectric polymer with enhanced energy density. J. Am. Ceram. Soc. 2013, 96, 2519-2524. [CrossRef]

76. Fan, M.Z.; Hu, P.H.; Dan, Z.K.; Jiang, J.Y.; Sun, B.Z.; Shen, Y. Significantly increased energy density and discharge efficiency at high temperature in polyetherimide nanocomposites by a small amount of $\mathrm{Al}_{2} \mathrm{O}_{3}$ nanoparticles. J. Mater. Chem. A 2020, 8, 24536-24542. [CrossRef]

77. Zhang, X.; Wang, F.; Dou, L.; Cheng, X.; Si, Y.; Yu, J.; Ding, B. Ultrastrong, superelastic, and lamellar multiarch structured $\mathrm{ZrO}_{2}-\mathrm{Al}_{2} \mathrm{O}_{3}$ nanofibrous aerogels with high-temperature resistance over 1300 degrees C. ACS Nano 2020, 14, 15616-15625. [CrossRef]

78. Hu, P.H.; Sun, W.D.; Fan, M.Z.; Qian, J.F.; Jiang, J.Y.; Dan, Z.K.; Lin, Y.H.; Nan, C.W.; Li, M.; Shen, Y. Large energy density at high-temperature and excellent thermal stability in polyimide nanocomposite contained with small loading of $\mathrm{BaTiO}_{3}$ nanofibers. Appl. Surf. Sci. 2018, 458, 743-750. [CrossRef]

79. Guo, F.M.; Shen, X.; Zhou, J.M.; Liu, D.; Zheng, Q.B.; Yang, J.L.; Jia, B.H.; Lau, A.K.T.; Kim, J.-K. Highly thermally conductive dielectric nanocomposites with synergistic alignments of graphene and boron nitride nanosheets. Adv. Funct. Mater. 2020, 30, 1910826. [CrossRef]

80. Kuang, B.Y.; Song, W.L.; Ning, M.Q.; Li, J.B.; Zhao, Z.J.; Guo, D.Y.; Cao, M.S.; Jin, H.B. Chemical reduction dependent dielectric properties and dielectric loss mechanism of reduced graphene oxide. Carbon 2018, 127, 209-217. [CrossRef]

81. Lin, M.Y.; Li, Y.H.; Xu, K.; Ou, Y.H.; Su, L.F.; Feng, X.; Li, J.; Qi, H.S.; Liu, D.T. Thermally conductive nanostructured, aramid dielectric composite films with boron nitride nanosheets. Compos. Sci. Technol. 2019, 175, 85-91. [CrossRef]

82. Liang, G.D.; Sun, G.X.; Bi, J.Q.; Wang, W.L.; Yang, X.N.; Li, Y.H. Mechanical and dielectric properties of functionalized boron nitride nanosheets / silicon nitride composites. Ceram. Int. 2021, 47, 2058-2067. [CrossRef]

83. Zhou, Y.; Li, Q.; Dang, B.; Yang, Y.; Shao, T.; Li, H.; Hu, J.; Zeng, R.; He, J.; Wang, Q. A scalable, high-throughput, and environmentally benign approach to polymer dielectrics exhibiting significantly improved capacitive performance at high temperatures. Adv. Mater. 2018, 30, e1805672. [CrossRef]

84. Li, H.; Ai, D.; Ren, L.; Yao, B.; Han, Z.; Shen, Z.; Wang, J.; Chen, L.Q.; Wang, Q. Scalable polymer nanocomposites with record high-temperature capacitive performance enabled by rationally designed nanostructured inorganic fillers. Adv. Mater. 2019, 31, e1900875. [CrossRef] 